\title{
GaN-based ZVS Bridgeless Dual-SEPIC PFC Rectifier with Integrated Inductors
}

Liu, Yunfeng; Huang, Xiaosheng; Dou, Yi; Ouyang, Ziwei ; Andersen, Michael A. E.

Published in:

IEEE Transactions on Power Electronics

Link to article, DOI:

10.1109/TPEL.2021.3070961

Publication date:

2021

Document Version

Peer reviewed version

Link back to DTU Orbit

Citation (APA):

Liu, Y., Huang, X., Dou, Y., Ouyang, Z., \& Andersen, M. A. E. (2021). GaN-based ZVS Bridgeless Dual-SEPIC PFC Rectifier with Integrated Inductors. IEEE Transactions on Power Electronics, 36(10), 11483-11498. https://doi.org/10.1109/TPEL.2021.3070961

\section{General rights}

Copyright and moral rights for the publications made accessible in the public portal are retained by the authors and/or other copyright owners and it is a condition of accessing publications that users recognise and abide by the legal requirements associated with these rights.

- Users may download and print one copy of any publication from the public portal for the purpose of private study or research.

- You may not further distribute the material or use it for any profit-making activity or commercial gain

- You may freely distribute the URL identifying the publication in the public portal 


\title{
GaN-based ZVS Bridgeless Dual-SEPIC PFC Rectifier with Integrated Inductors
}

\author{
Yunfeng Liu, Student Member, IEEE, Huang Xiaosheng, Member, IEEE, Yi Dou, Student Member, IEEE, Ziwei \\ Ouyang, Senior Member, IEEE, and Michael A. E. Andersen, Member, IEEE
}

\begin{abstract}
This paper investigates the gallium nitride (GaN) based bridgeless dual single-ended primary inductor converter (SEPIC) power factor correction (PFC) with full input voltage range zero-voltage-switching (ZVS) turn-on for the application of step down AC-DC converter. The operation principle for the bridgeless Dual-SEPIC PFC and the theoretical analysis for the ZVS operation has been investigated. Furthermore, a new magnetic integration has been proposed to assemble all three inductors, including one input inductor and two output side inductors into one E-I-E core. The integrated inductor reduces the total ferrite volume and makes the converter more compact. The inductance design for ZVS SEPIC PFC and the magnetic reluctance modeling for the $E$-I-E core with the coupled inductor has been analyzed. The effective equivalent inductance of the input inductor can be implemented with a much less number of turns by a carefully designed coupling coefficient. Finally, a 300W GaN-based MHz bridgeless Dual-SEPIC PFC with the integrated inductors is developed and tested with full-range ZVS, 97\% peak efficiency based on the ZVS extension strategy.

Index Terms: Bridgeless SEPIC PFC, integrated inductors, ZVS turn-on, E-I-E core.
\end{abstract}

\section{INTRODUCTION}

The main power supplies used in telecom, on-board chargers, servers, and industrial PSU systems need to convert the AC line power to a constant DC output voltage. Thus, rectifiers have been employed unavoidably. These systems usually range from a hundred watts to several kilowatts. The major problem for conventional rectifiers is severe harmonic pollution. Therefore, front-end power factor correction (PFC) converters are widely used to shape the input current of the power supply to meet the power factor (PF) standard and the current THD norms such as IEC 61000-3-2 [1]-[3].

As the most efficient and simple PFC circuit, the boost type PFC is extensively adopted. Because of the intrinsic boost characteristic, the output voltage of the boost PFC must be higher than the peak of the AC line voltage, which is typically $400 \mathrm{~V}$ [4]-[8]. Thus, in some step-down applications, a second stage is required to convert the output voltage of the boost PFC to a specific voltage lower than the peak input AC voltage. The two-stage converter will degrade the system efficiency as well as the power density. Therefore, the SEPIC PFC is prevailing in those applications. The output voltage of SEPIC PFC can be regulated either higher or lower than the AC input voltage. Thus, SEPIC converters are widely employed in LED lighting systems, wireless power transfer systems, standalone photovoltaic systems, and portable power applications [9],[10].

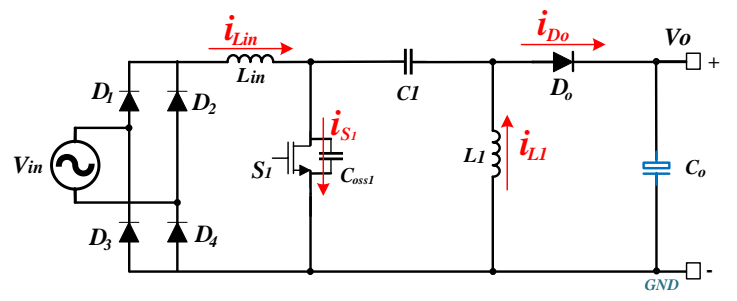

(a)

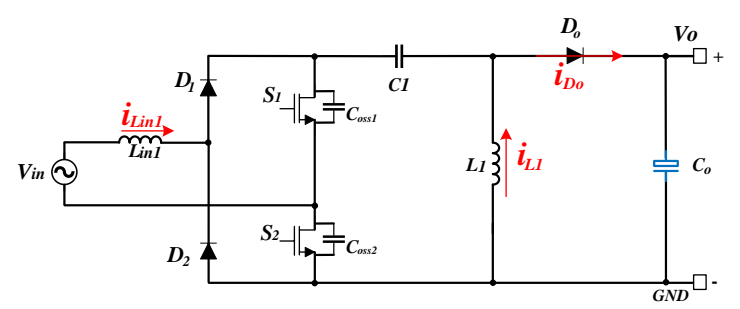

(b)

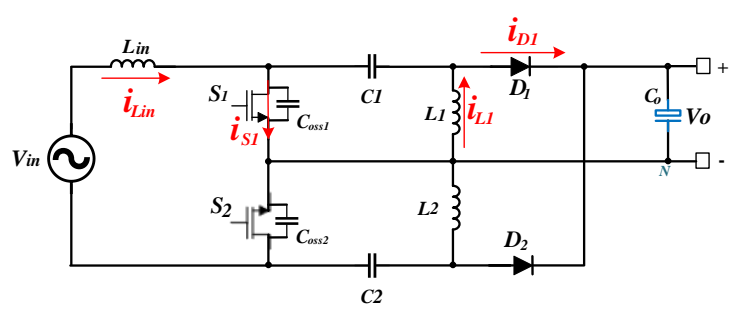

(c)

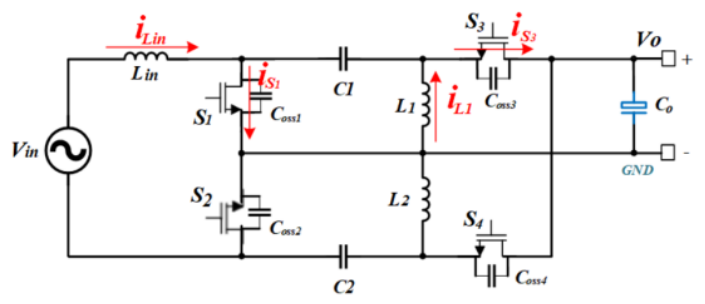

(d)

Fig. 1. (a) Conventional Sepic PFC with the diode bridge rectifier. (b) Type I bridgeless SEPIC PFC. (c) Type II bridgeless Dual SEPIC PFC. (d) modified bridgeless Dual SEPIC PFC.

The conventional SEPIC PFC consists of a bridge rectifier followed by a DC-DC SEPIC converter, as shown in Fig. 1(a) [9]-[13]. The high conduction loss caused by the forward voltage drop of the diode bridge rectifier will degrade the overall system efficiency dramatically, and the heat generated by the bridge rectifier may need an extra heatsink. Hence, to increase the power supply efficiency, the bridgeless SEPIC 


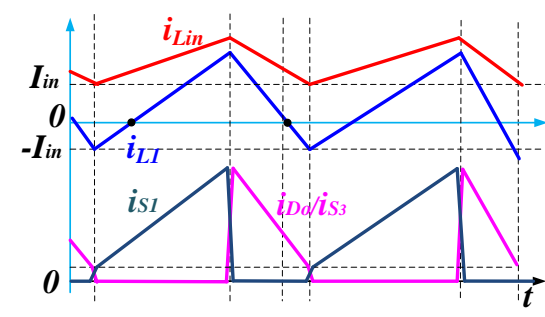

(a)

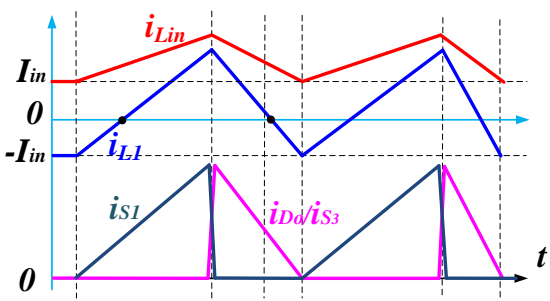

(b)

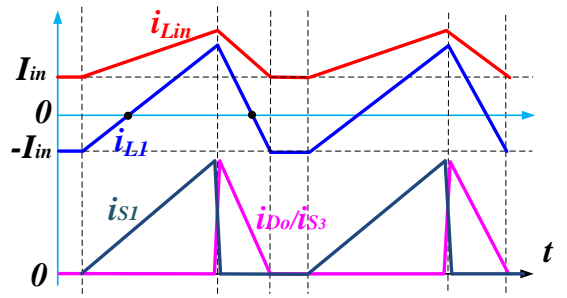

(c)

Fig. 2. Three operation modes for Sepic PFC. (a) CCM. (b) CRM. (c) DCM.

PFC circuit topologies have been extensively researched [14][30]. Fig.1 (b) [19]-[21] and Fig.1(c) [18], [25]-[27] are two typical types bridgeless SEPIC PFC topologies. Without the forward bridge rectifier, it allows the current to flow through a minimum number of semiconductor devices. Thus, the converter conduction losses can be significantly reduced. The Type I bridgeless SEPIC PFC in Fig.1 (b) has two more diodes on the input side that will introduce more conduction loss. The Type II bridgeless SEPIC PFC in Fig.1(c) has two more passive components.

To reduce the volume of the passive component, increasing the switching frequency has been proved as an effective method [7]. The emerging of $\mathrm{GaN}$ devices, which have a low on-resistance, fast switching speed, and zero reverse recovery loss, have pushed the switching frequencies to the megahertz range for power electronics equipment [39]. Thus, the size of the magnetic components has been dramatically reduced. Since the state-of-the-art SEPIC PFC prototypes mainly work under discontinuous conduction mode (DCM), the converters are operating in hard switching, which will still cause a substantial turn-on power loss when the switching frequency increased. Hence, the switching frequency of the state-of-theart SEPIC PFC ranges from tens to hundreds of $\mathrm{kHz}$, it has still big challenge to push the switching frequency to megahertz.

To further increase the switching frequency, the switching loss must be dealt with. In particular, the turn-on loss of GaN FET dominates the power loss and is the major limitation for achieving high efficiency. Conventional SEPIC PFC with the output diode has low efficiency at high switching frequency since the ZVS operation cannot be obtained for all switches. [9],[13]. Thus, the realization of ZVS for the main switch is a key point to design a high-frequency, high-efficiency SEPIC $\mathrm{PFC}$ rectifier.

Some researches have been done to implement ZVS for SEPIC PFC [10],[30,[31]. In [30], a soft-switching cell composed of an active switch, a resonant inductor, and a resonant capacitor was applied into the SEPIC PFC to obtain ZVS to promote the converter efficiency. The active clamped SEPIC PFC was studied in [10] and [31]. By adding extra clamping capacitance and MOSFET, partial ZVS can be achieved. However, All the existing studies cannot accomplish the fully ZVS operation without adding any auxiliary components. This paper investigates the bridgeless dual SEPIC PFC with the full range ZVS for all switches, as shown in Fig. 1(d). By replacing the output diode with MOSFET, the negative current is provided for main switches $\mathrm{S} 1 / \mathrm{S} 2$ to discharge the output capacitors. So ZVS is guaranteed in the full range of the input voltage. Thus, without adding any extra components, it can maximize efficiency at a high switching frequency.

The comparison of the three bridgeless SEPIC PFC topologies is shown in Table I. By integrating all the three discrete inductors of the proposed topology in one E-I-E magnetic core, it has 7 components in total, which has the minimum components among the three topologies. In addition, there are no diodes in the line current path. For conventional two types bridgeless SEPIC PFC, the ZVS turn-on cannot be fully achieved, which will limit the switching frequency as well as the efficiency.

Table I

Comparison of three Bridgeless SEPIC topologies

\begin{tabular}{cccc}
\hline \hline Count & $\begin{array}{c}\text { Type I Bridgeless } \\
\text { SEPIC PFC }\end{array}$ & $\begin{array}{c}\text { Type II Bridgeless } \\
\text { SEPIC PFC }\end{array}$ & $\begin{array}{c}\text { Modified } \\
\text { SEPIC PFC }\end{array}$ \\
\hline MOSFET & 2 & 2 & 4 \\
Diode & 3 & 2 & 0 \\
Inductor & 2 & 3 & $3 \rightarrow 1$ \\
Capacitor & 1 & 2 & 2 \\
\hline Total & 8 & 9 & $9 \rightarrow 7$ \\
\hline ZVS & Partial & Partial & Full range \\
\hline \hline
\end{tabular}

The operation mode of the conventional PFC can be roughly classified into three categories depending on the waveform of the input inductor current, namely, the continuous conduction mode (CCM), the critical conduction mode (CRM), and the discontinuous conduction mode (DCM) [36]. In CRM mode, ZVS can be achieved with the correct digital control for the boost-type PFC [6]-[8],[38]-[40]. However, when it comes to the SEPIC PFC, the operation mode cannot be classified with the same principle because SEPIC PFC consists of two inductors. In contrast, the operation mode is determined by the sum of two inductor current $\left(i_{L i n}+i_{L I}\right)$, which is the current flows through the main switch $S_{I}$ when $S_{l}$ is ON. When $S_{l}$ is OFF, and $S_{3}$ is ON, $\left(i_{L i n}+i_{L I}\right)$ is output current $i_{S 3}$ flow through the synchronous switch $S_{3}$. The input inductor current $i_{\text {Lin }}$ commonly designs to work at continuous conduction mode. The inductor current waveforms of SEPIC PFC for three operation modes are depicted in Fig. 2. If the main switch $S_{I}$ turns on when $i_{S 3}$ is exactly decreased to zero, this is CRM mode, as shown in Fig. 


\section{IEEE POWER ELECTRONICS REGULAR PAPER}

2(b). If the main switch $S_{1}$ turns on before the $i_{S 3}$ decease to zero, this is CCM. Otherwise, it is DCM.

The DCM has been widely used for SEPIC PFC because of the ZCS turn-off for the diode [8]-[29]. However, the ZVS cannot be achieved in DCM mode. The modified bridgeless SEPIC PFC is working under CRM mode (also call boundary conduction mode, BCM) by adding extended conduction time for the synchronous MOSFET device. However, the input inductor still works under continuous conduction mode with a small current ripple even the converter is working in DCM or CRM mode, which may increase the system efficiency and minimize the volume of the EMI filter design.

To further make the converter more compact and reduce the cost, the integrated inductors have been investigated for the bridgeless Dual-SEPIC PFC in this paper. In the DC-DC SEPIC converter, the integrated inductor has been used [33][34]. By tightly coupled the input inductor and output inductor, the effective inductance can be double, and thus the current ripple can be reduced. For the AC-DC SEPIC PFC converter, this integrated inductor usually applied to dualphase interleaved SEPIC PFC with a bridge rectifier [11],[12], the two input inductors, and two output inductors integrated separately with different magnetic cores. In [37], two integrated inductors have been conducted for the four inductors of the bridgeless SEPIC PFC. Still, two magnetics core needed. This paper proposed the integrated inductors, making it possible to assemble all the three inductors of the bridgeless Dual-SEPIC PFC into one E-I-E magnetic core. Based on the equivalent magnetic reluctance model, the theoretical analysis shows that the equivalent inductance can be enlarged several times to the self-inductance. The effective equivalent inductance of the input inductor can be implemented with fewer turns by an appropriately designed coupling coefficient.

In this paper, the full-range ZVS for the bridgeless GaNbased $\mathrm{MHz}$ Dual-SEPIC PFC is achieved. The operation principle of the topology and the ZVS control is investigated. Then the integrated inductors are designed to assemble all the magnetic components into one E-I-E magnetic core. The inductance design for the bridgeless SEPIC PFC and the magnetic modeling for the E-I-E core with the coupled inductor has been analyzed.

This paper is organized as follows. The principle of the operation stage and the theoretical analysis of ZVS implementation are presented in Section II. The inductance design and the coupling coefficient selection are presented in Section III. Hardware implementation is introduced in Section IV. Furthermore, a $300 \mathrm{~W}$ prototype of the SEPIC PFC is demonstrated, and the experimental results are shown in Section V, and Section VI concludes this paper.

\section{ANALYSIS OF THE Dual-SEPIC PFC TOPOLOGY}

\section{A. Principle of operation}

The bridgeless Dual-SEPIC PFC converter has two identical SEPIC converters, each operating in alternate half-line cycles, based on the polarity of the input AC voltage. It consists of three inductors: one input inductor $L_{i n}$ and two output inductors $L_{1}, L_{2} . L_{1}$ and $L_{\text {in }}$ conduct at the positive half-line cycle, and $L_{2}$ and $L_{i n}$ conduct at the negative half-line cycle. $S_{2}$ is always ON, and $S_{4}$ is always OFF in the positive half-line cycle. In the negative half-line cycle, $S_{1}$ is always $\mathrm{ON}$, and $S_{3}$ is always OFF. The analysis and discussions of the positive half-line cycle are similar to the negative half-line cycle, so only the positive half-line cycle has been analyzed in this paper. Assuming the input current $i_{\text {Lin(t) }}$ is in phase with the input voltage $V_{i n(t)}$, defining the input AC line voltage and input current as:

$$
\begin{aligned}
& V_{\text {in }}(t)=\sqrt{2} \cdot V_{\text {in_rms }} \cdot \sin \left(w_{\text {line }} t\right) \\
& i_{\text {Lin }}(t)=\sqrt{2} \cdot I_{\text {in_rms }} \cdot \sin \left(w_{\text {line }} t\right)
\end{aligned}
$$

Where $V_{\text {in_rms }}$ and $I_{\text {in_rms }}$ are the input RMS voltage and RMS current, $w_{\text {line }}=2 \pi f_{\text {line }}$, and $f_{\text {line }} i$ s the line frequency.

Fig. 3 shows the theoretical current waveforms in the positive half-line cycle. The input inductor $L_{i n}$ works under continuous conducting mode with a small current ripple. When $S_{1}$ is $\mathrm{ON}$, and $S_{3}$ is OFF, the switch current, $i_{S 1}$ is the sum of $i_{L i n}$ and $i_{L I}$. When $S_{1}$ is OFF, and $S_{3}$ is ON, the output current $i_{S 3}$ is the sum of $i_{L i n}$ and $i_{L 1}$. A typical waveform of the inductor current in each switching cycle is shown in Fig. 4. $D_{O N}$ is the turn-on duty cycle for $S_{l}$. According to the operation principle, the instantaneous current of $S_{1}$ and $S_{3}$ in each switching cycle can be expressed as

$$
\begin{aligned}
& i_{S 1}(t)=\left\{\begin{array}{lc}
i_{L i n}(t)+i_{L 1}(t), & 0<t<D_{O N} \cdot T_{S} \\
0, & D_{O N} \cdot T_{S}<t<T_{S}
\end{array}\right. \\
& i_{S 3}(t)=\left\{\begin{array}{lc}
0, & 0<t<D_{O N} \cdot T_{S} \\
i_{\text {Lin }}(t)+i_{L 1}(t) & D_{O N} \cdot T_{S}<t<T_{S}
\end{array}\right.
\end{aligned}
$$

When $S_{1}$ turns OFF, and $S_{3}$ turns ON, the average current of $S_{3}$ in each switching cycle can be obtained as

$$
i_{S 3_{-} a v g}(t)=\frac{i_{S 3_{-} p k} \cdot T_{O F F}}{2 \cdot T_{S}}=\frac{\left(i_{L_{\text {Lin }} p k}+i_{L 1_{-} p k}\right) \cdot T_{O N} \cdot V_{i n}(t)}{2 \cdot T_{S} \cdot V_{O}}
$$

Then the average of $S_{3}$ in the half-line cycle is derived

$$
I_{S 3_{-} \text {avg }}=\frac{1}{\pi} \cdot \int_{0}^{\pi} i_{S 3_{-} a v g}(t) \cdot d t=\frac{V_{i n_{-} r m s}{ }^{2} \cdot\left(L_{1}+L_{i n}\right) \cdot T_{O N}{ }^{2}}{2 \cdot L_{1} \cdot L_{i n} \cdot T_{S} \cdot V_{O}}
$$

Substituting $I_{S 3_{-} a v g}=P_{O} / V_{O}$, based on (1) to (6), $T_{O N}$ and $T_{O F F}$ yields

$$
\begin{gathered}
T_{O N}=\frac{V_{O}}{V_{\text {in_rms }}} \cdot \sqrt{\frac{2 \cdot L_{1} \cdot L_{i n} \cdot T_{S}}{\left(L_{1}+L_{i n}\right) \cdot R_{O}}} \\
T_{O F F}=\frac{V_{i n}(t)}{V_{O}} \cdot T_{O N}=\frac{V_{i n}(t)}{V_{r m s}} \cdot \sqrt{\frac{2 \cdot L_{1} \cdot L_{i n} \cdot T_{S}}{\left(L_{1}+L_{i n}\right) \cdot R_{O}}}
\end{gathered}
$$

Since $T_{O N}+T_{O F F}=T_{S}=1 / f_{S}$ under CRM mode, hence the switching frequency is

$$
f_{S}(t)=\frac{\left(L_{i n}+L_{1}\right) \cdot V_{O}^{2} \cdot V_{i n_{-} r m s}^{2}}{2 \cdot P_{O} \cdot L_{i n} \cdot L_{1} \cdot\left(V_{i n}(t)+V_{O}\right)^{2}}
$$

In Fig. 5, the red line shows the theoretical analysis variable switching frequency for CRM mode of the bridgeless DualSEPIC PFC during the half-line cycle. It can be seen that the 


\section{IEEE POWER ELECTRONICS REGULAR PAPER}

maximum switching frequency occurs in the crossing section of the line cycle, and the minimum switching frequency occurs in the middle of the half-line cycle when the input voltage reaches the peak value.

To achieve ZVS for the main switch $S_{l}$, the negative current of $i_{S I}$ is needed to discharge the output capacitors of $S_{I}$. The conventional SEPIC PFC can not provide the discharged negative current. In order to obtain the negative current, the output diode $D_{o}$ is replaced by the MOSFET $S_{3}$. Then $S_{3}$ turns OFF when $i_{S 3}$ declined to the required negative current rather than zero, i.e., $i_{S 3}=i_{L i n}+i_{L I} \leqslant 0$; after $S_{3}$ is OFF, the negative current will transfer to $i_{S I}$ to realize ZVS for $S_{l}$.

To limit the high switching frequency at the crossing section of the AC line cycle, the maximum switching frequency is limited to $1 \mathrm{MHz}$. Moreover, the practical switching frequency is shown as the blue dash line. The practical switching frequency is lower than the theoretical switching frequency because the extended conduction time is added to the synchronous switch $S_{3}$.

Assuming the intermediate capacitors $C_{1}$ and $C_{2}$ are large enough, the voltage ripples of $C_{1}$ and $C_{2}$ in each switching cycle are negligible. And the voltage ripple of the AC input voltage $V_{i n}(t)$ also can be seemed as a constant value since the switching frequency is much higher than the line frequency, i.e., $V_{C I}=V_{\text {in }}(t)=V_{\text {in }}\left(t_{0}\right)$. The value is selected at the beginning of each switching cycle. Based on the aforementioned assumptions, the circuit operation can be divided into six stages, separated by time instants $\left(t_{0}, t_{1} \ldots t_{6}\right)$, as marked in Fig. 4. The equivalent circuit of each stage is given in Fig. 6, and the corresponding analytical model is derived.

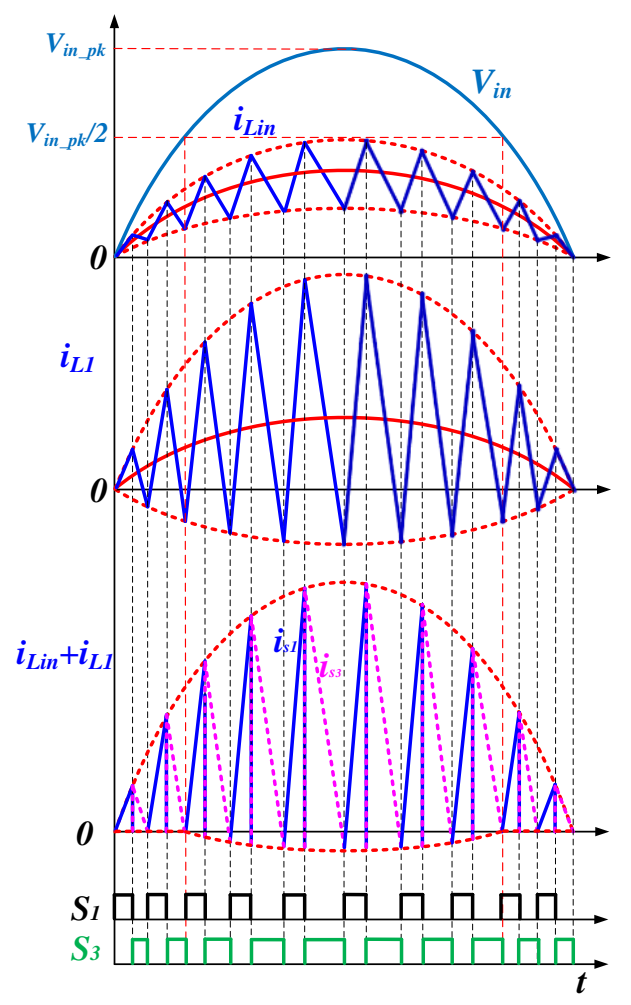

Fig. 3. The current waveform during the positive half-line cycle.

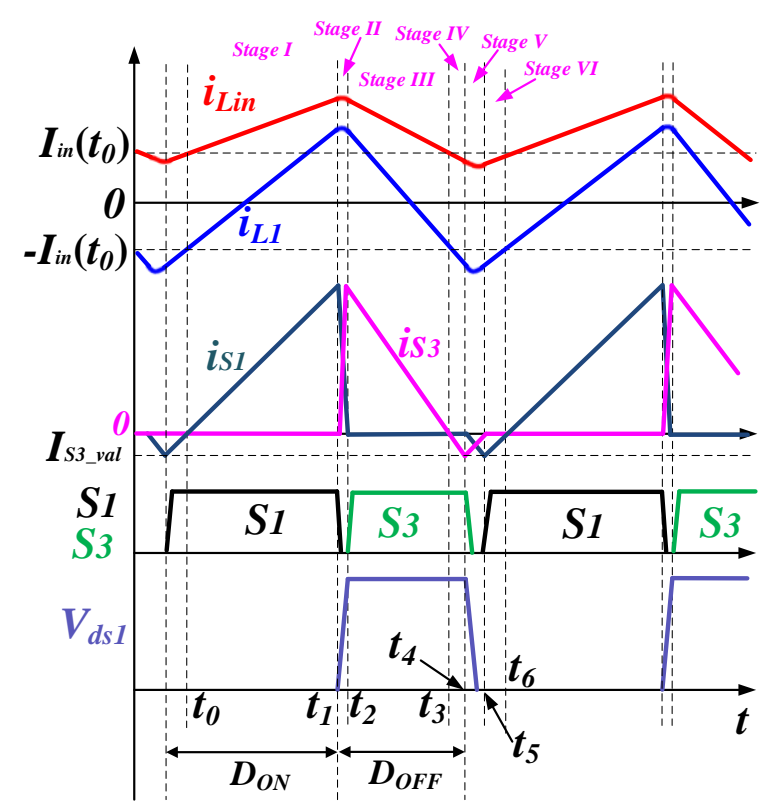

Fig. 4. Typical current waveform in each switching cycle.

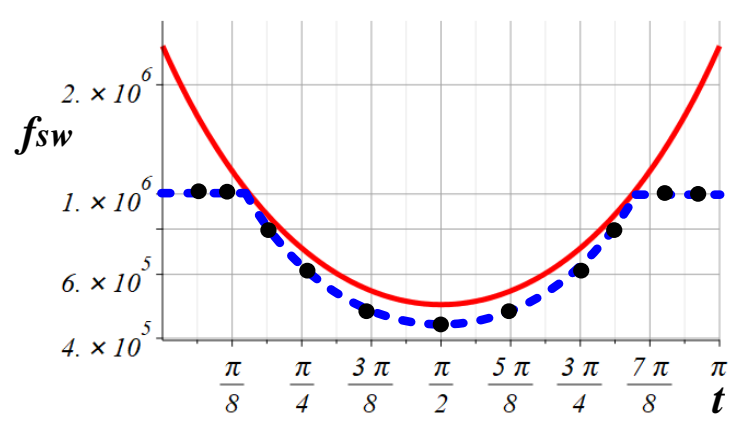

Fig. 5. Variable switching frequency during half-line cycle.

1) Stage I $\left(t_{0}-t_{1}\right)$ :

As shown in Fig. 4, this stage starts when the switch current $i_{S l}$ crosses zero. The equivalent circuit is shown in Fig. 6(a), $L_{i n}$ is charged by the input voltage, and $L_{l}$ is charged by the intermediate capacitor $C_{l}$. The voltages of both inductors $L_{l}$ and $L_{\text {in }}$ equal to $V_{i n}\left(t_{0}\right)$. Hence, the inductor current $i_{L i n}$ and $i_{L I}$ starts to rise linearly. Based on the operation mentioned above, the following equations can be obtained:

$$
\left\{\begin{array}{l}
i_{\text {Lin }}(t)=I_{\text {in }}\left(t_{0}\right)+\frac{V_{\text {in }}\left(t_{0}\right)}{L_{\text {in }}}\left(t-t_{0}\right) \\
i_{L 1}(t)=-I_{\text {in }}\left(t_{0}\right)+\frac{V_{\text {in }}\left(t_{0}\right)}{L_{1}}\left(t-t_{0}\right) \\
i_{S 1}\left(t_{1}\right)=i_{L 1}(t)+i_{\text {Lin }}(t)=\frac{V_{\text {in }}\left(t_{0}\right)}{L_{\text {eq }}}\left(t-t_{0}\right) \geq 0 \\
i_{S 3}(t)=0
\end{array}\right.
$$

Where $I_{i n}\left(t_{0}\right)$ is the average input current, $L_{e q}$ is the equivalent inductor $L_{e q}=L_{1} \cdot L_{\text {in }} /\left(L_{1}+L_{\text {in }}\right)$. 


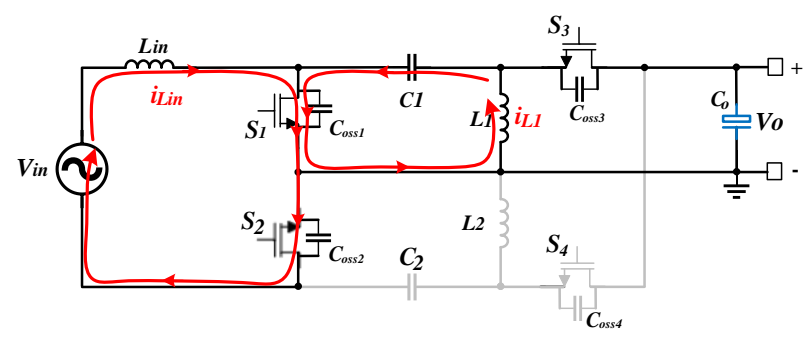

(a)

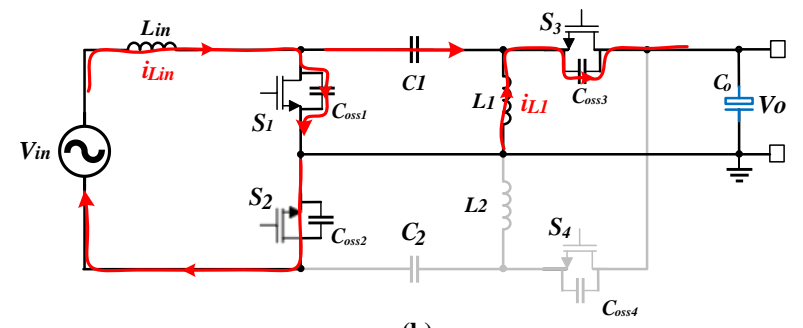

(b)

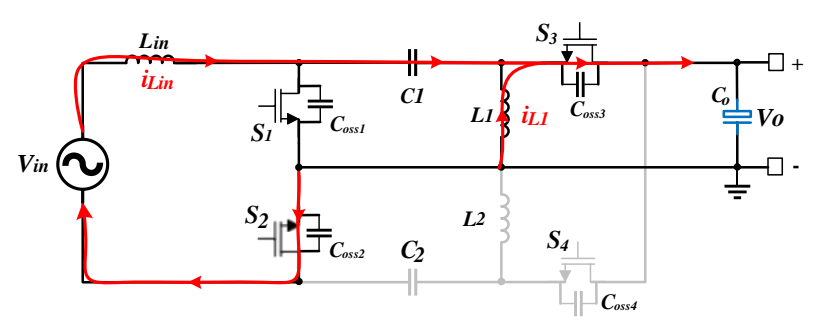

(c)

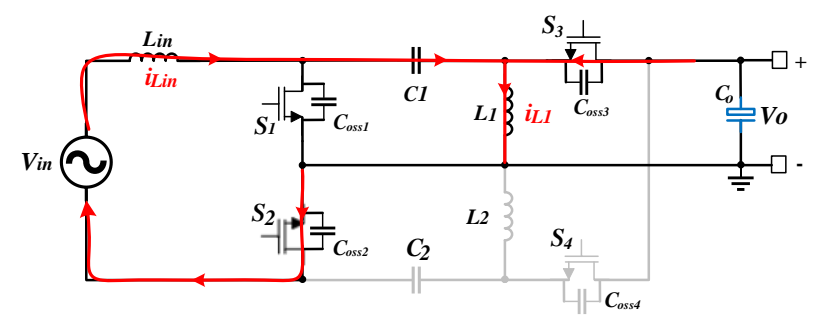

(d)

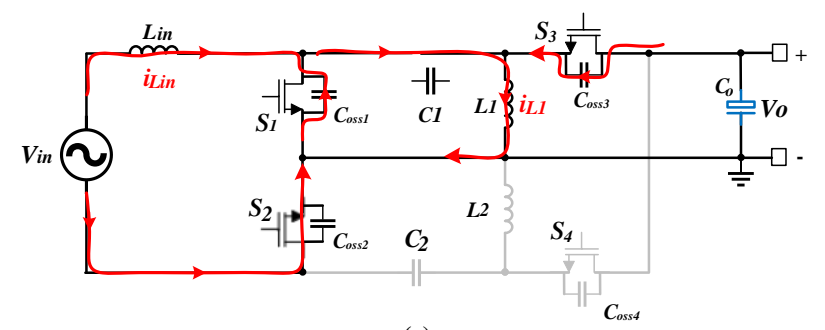

(e)

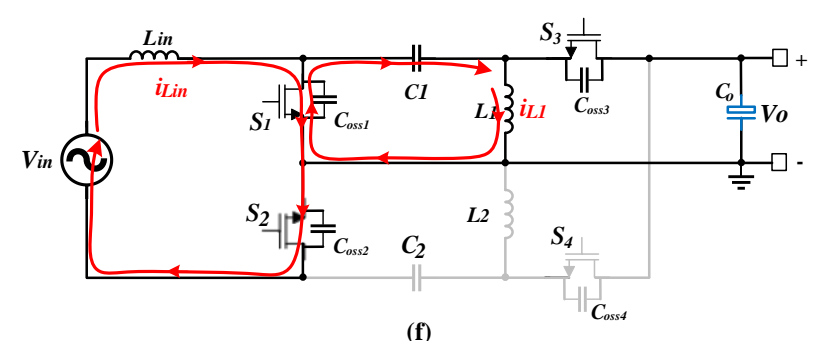

(f)

Fig. 6. Six operation stages for the modified SEPIC PFC. (a) Stage I. (b) Stage II. (c) Stage III. (d) Stage IV. (e) Stage V. (f) Stage VI.

\section{2) Stage II (t1-t2):}

Stage II starts at $t_{l}$ when $S_{l}$ is OFF, as shown in Fig. 6(b), $S_{3}$ is also in the OFF state and ready to turn ON. The two parallel GaNFETs output capacitors $C_{\text {oss }}$ and $C_{\text {oss }}$, begin to resonate with the two parallel inductors $L_{i n}$ and $L_{1}$. During this resonant period, $C_{o s s l}$ is charged while $C_{\text {oss } 3}$ is discharged simultaneously. This stage ends when the voltage of $C_{\text {oss }}$ is charged from 0 to $\left(V_{i n}+V_{o}\right)$, and the voltage of $C_{o s s}$ is released from $\left(V_{i n}+V_{o}\right)$ to 0 . In this short resonant transition period, the currents of $i_{L i n}$ and $i_{L l}$ can be seemed as constant.

3) Stage III ( $\left.t_{2}-t_{3}\right)$ :

This stage begins by turning $S_{3} \mathrm{ON}$ at $t_{2}$. Since the $C_{o s s 3}$ of $S_{3}$ is already discharged to zero, thus ZVS of $S_{3}$ is realized. The input inductor current $i_{\text {Lin }}$ and the output inductor current $i_{L I}$ flow through $S_{3}$ to the load, and both inductor voltages are $-V_{o}$. This stage ends when the current of $i_{S 3}$ drops to zero at $t_{3}$. The equations of the currents can be obtained:

$$
\left\{\begin{array}{l}
i_{\text {Lin }}(t)=i_{\text {Lin }}\left(t_{2}\right)-\frac{V_{o}}{L_{\text {in }}}\left(t-t_{2}\right) \\
i_{L 1}(t)=i_{L 1}\left(t_{2}\right)-\frac{V_{o}}{L_{1}}\left(t-t_{2}\right) \\
i_{S 1}(t)=0 \\
i_{S 3}(t)=i_{L 1}\left(t_{2}\right)+i_{\text {Lin }}\left(t_{2}\right)-\frac{V_{o}\left(t_{0}\right)}{L_{e q}}\left(t-t_{2}\right)>0
\end{array}\right.
$$

4) Stage IV (t3-t4):

For the conventional SEPIC PFC shown in Fig. 1(a) to Fig. 1(c), the output diode Do turns OFF automatically when the diode current $i_{D o}$ declines to zero. However, the main switch $S_{3}$ of the modified Dual-SEPIC PFC remains ON after the switch current $i_{S 3}$ reaches zero. $i_{S 3}$ continues to decrease by adding an extended conduction time $T_{e x}$ as shown in Fig. 4 from $t_{3}$ to $t_{4}$, here $T_{e x}=t_{4}-t_{3}$. Thus, after $S_{3}$ is OFF, the negative current is transferred to $S_{l}$. Hence, the negative current is provided to discharge $C_{\text {oss }}$ to achieve ZVS for $S_{l}$. As shown in Fig. 6(d), the equivalent circuit is the same as Stage III, except for the polarity of current $i_{S 3}$. This stage ends when $i_{S 3}$ drops to the required negative current value $I_{S 3_{2} \text { val }}$ for $\mathrm{ZVS}$ realization.

$$
i_{S 3}(t)=i_{L 1}\left(t_{2}\right)+i_{\text {Lin }}\left(t_{2}\right)-\frac{V_{o}\left(t_{0}\right)}{L_{e q}}\left(t-t_{2}\right)<0
$$

Thus, $I_{S 3_{-} \text {val }}$ can be expressed as

$$
I_{S 3_{-} v a l}=-\frac{V_{o}\left(t_{0}\right)}{L_{e q}} T_{e x}<0
$$

5) Stage $V(t 4-t 5)$ :

This stage is also a resonated stage, which is similar to Stage II. It starts when $S_{3}$ is OFF at $t_{4}$. Then the negative current in $S_{3}$ is transferred to $S_{l}$. The two parallel GaNFETs output capacitors $C_{\text {oss }}$ and $C_{\text {oss }}$ start to resonate with the two parallel inductors. During this resonant period, the voltage of $C_{o s s l}$ is discharging from $\left(V_{i n}+V_{o}\right)$ to 0 , and the voltage of the $C_{o s s}$ is discharged from 0 to $\left(V_{i n}+V_{o}\right)$, as shown in Fig. 6(e). This stage ends when $S_{l}$ turns on. Here assuming that $C_{\text {oss }}=$ 


\section{IEEE POWER ELECTRONICS REGULAR PAPER}

$C_{\text {oss } 3}=C_{\text {oss }}$, the input voltage is considered as constant value as $V_{i n}=V_{i n}\left(t_{0}\right)$. The voltages of $C_{o s s}$ and $C_{o s s} 3$ are $V_{d s l}(t)$ and $V_{d s 3}(t)$. The inductor current $i_{S 3}$ and the voltages $V_{d s l}(t), V_{d s 3}(t)$ can be expressed by the equations below:

$$
\left\{\begin{array}{l}
i_{S 3}(t)=I_{S 3} \cdot \cos \left(w_{0} t\right)-\frac{V_{o}}{Z_{n}} \sin \left(w_{0} t\right) \\
V_{d s 1}(t)=V_{i n}+V_{o} \cdot \cos \left(w_{0} t\right)+I_{S 3} \cdot Z_{n} \sin \left(w_{0} t\right) \\
V_{d s 2}(t)=V_{o}-V_{o} \cdot \cos \left(w_{0} t\right)-I_{S 3} \cdot Z_{n} \sin \left(w_{0} t\right) \\
w_{o}=1 / \sqrt{L_{e q} C_{e q}}, Z_{n}=\sqrt{L_{e q} / C_{e q}}, C_{e q}=C_{o s s 1}+C_{o s s 3}
\end{array}\right.
$$

Where $Z_{n}$ is the characteristic impedance in the resonant period. $C_{e q}$ is the equivalent capacitor. $w_{o}$ is the resonant angular frequency. $I_{S 3}=I_{L 1}+I_{L i n}$, where $I_{L i n}$ and $I_{L 1}$ are the inductor current value at the beginning of the resonant stage. Based on (14), then the following equation can be obtained:

$$
Z_{n}{ }^{2} \cdot i_{S 3}(t)^{2}+\left(V_{d s 1}(t)-V_{i n}\right)^{2}=I_{S 3}{ }^{2} \cdot Z_{n}{ }^{2}+V_{o}{ }^{2}
$$

It shows that the trajectory of the drain-source voltage $V_{d s}$ at this resonant stage is a circle, with the center at $\left(0, V_{i n}\right)$, and the radius is $\sqrt{I_{S 3}{ }^{2} \cdot Z_{n}{ }^{2}+V_{o}{ }^{2}}$, as shown in Fig. 7(c). For the conventional DCM SEPIC PFC with the diode, the $I_{D 0}=I_{L i n}+$ $I_{L I}=0$. Therefore the radius is $V o$ when the input voltage exceeds the output voltage $\left(V_{i n}>V_{O}\right)$. With a similar analysis, it also can be obtained that the radius is $V_{\text {in }}$ when $V_{\text {in }}<V_{O}$ for the conventional SEPIC PFC. The state plane trajectories for the conventional DCM SEPIC PFC are also shown in Fig. 7(a) and Fig. 7(b), respectively.

6) Stage VI (t5-t6):

This stage starts by turning $S_{1} \mathrm{ON}$ at $t_{5}$. Since the voltage of output capacitor $C_{\text {oss }}$ is already discharged to 0 in Stage $V$, hence the ZVS operation of $S_{l}$ is obtained. Both the two inductor currents flow through $S_{1}$, and the voltages across the two inductors are $V_{i n}$. This stage ends when the current of $i_{S I}$ rises to zero. Then another switching cycle starts as Stage I.

\section{B. Conditions for ZVS implementation}

Compared with the modified Dual-SEPIC PFC, the conventional DCM SEPIC PFC with the diode rectifier only has four stages because no negative output current existed. When the diode current $i_{D o}$ is decreased to zero, as shown in Fig. 7(d) $\left(V_{i n}<V_{O}\right)$ and Fig. 7(e) $\left(V_{i n}>V_{O}\right)$, the two parallel inductors start to resonate with the two parallel capacitors, including the output capacitor of $S_{l}$ and the parasitic capacitors of the diode $D_{O}$. The valley switching can be applied with the correct turn-on instant time control. Thus, the minimum value of $V_{d s I}$ is achieved at the valley switching is $\left(V_{i n}-V_{O}\right)$. Hence the ZVS for the conventional SEPIC PFC can only be achieved when the input voltage $V_{\text {in }}$ is lower than the output voltage $V_{o}$ as shown in Fig. 7(d). The state plane trajectories for conventional DCM SEPIC PFC shown in Fig. 7(a) $\left(V_{\text {in }}<V_{O}\right)$ and Fig. 7(b) $\left(V_{\text {in }}>V_{O}\right)$ also indicate that the ZVS operation can only be achieved when $V_{i n}<V_{O}$. As shown in Fig. 7(e), when the input voltage exceeds the output voltage, the minimum value of drain-source voltage $V_{d s}$ can only resonate to a valley point $\left(V_{i n}-V_{O}\right)$. Therefore, at least $0.5 C_{e q}\left(V_{i n}-V_{O}\right)^{2}$ power loss occurs when $S_{l}$ starts turning on.

In order to achieve the fully ZVS in the whole line cycle, the diode $D_{O}$ is replaced by the high-speed GaN device $S_{3}$, as shown in Fig. 1(d). And then the ZVS extension strategy explained in [6],[8],[39]-[41] is used. Then the negative current can be provided to guarantee the ZVS for the main

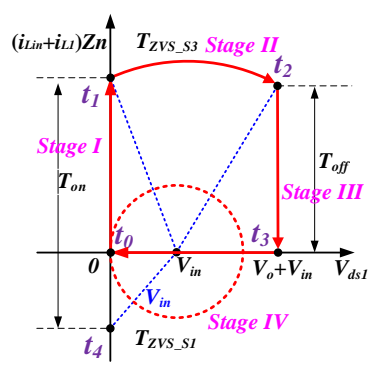

(a)

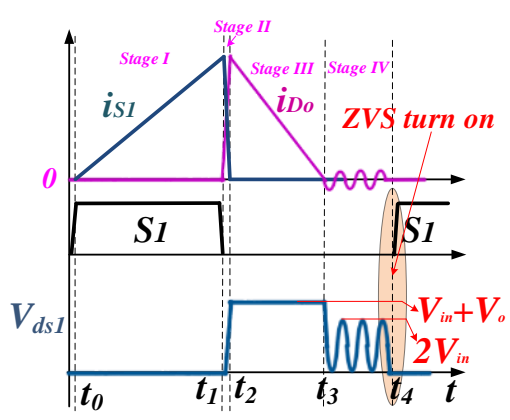

(d)

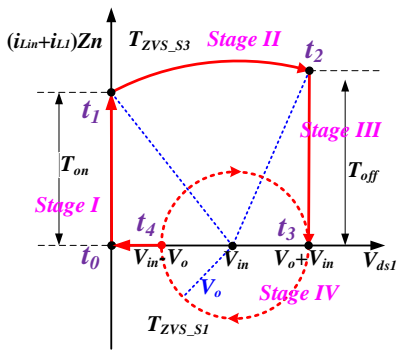

(b)

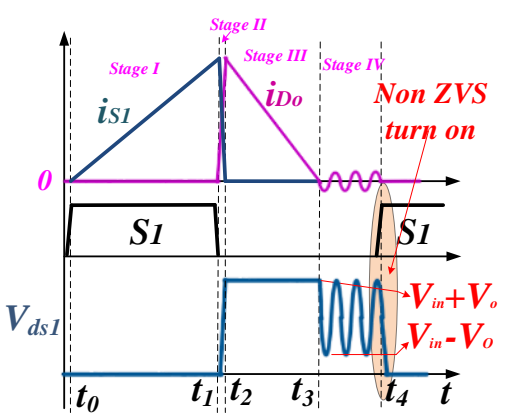

(e)

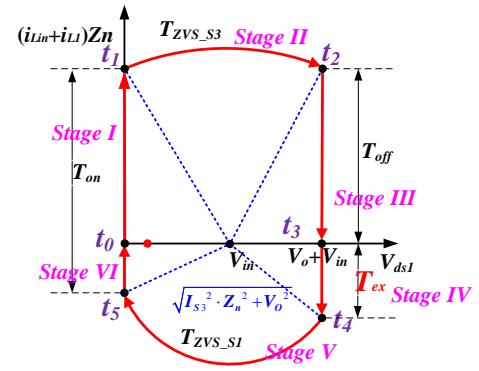

(c)

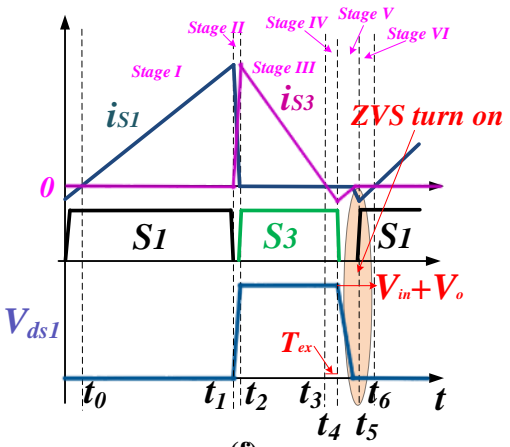

(f)

Fig. 7. (a). State plane trajectory for conventional SEPIC PFC when Vin $\leq 0.5$ Vo. (b). State plane trajectory for conventional SEPIC PFC when Vin $\geqslant 0.5 V o$. (c). State plane trajectory for the modified SEPIC PFC. (d). Operation waveforms for conventional SEPIC PFC when Vin $\leq 0.5$ Vo. (e). Operation waveforms for conventional SEPIC PFC when Vin $\geqslant 0.5 \mathrm{Vo}$. (f). Operation waveforms for the modified SEPIC PFC. 


\section{IEEE POWER ELECTRONICS REGULAR PAPER}

switch $S_{I}$. Thus, instead of automatically turning OFF the diode $D_{O}$ in DCM mode when the diode current decreases to zero, a short extended conduction time $T_{e x}$ is added on purpose for $S_{3}$ shown in Fig. 7(f) Stage IV (t3-t4). Then the negative current flows through $S_{1}$ is provided to discharge the output capacitor $C_{o s s}$ to help to achieve ZVS for the main switch $S_{l}$. It also can be seen from the state plane trajectory in Fig. 7(c), the negative current $i_{S 3}$ enlarges the radius from $V_{o}$ to $\sqrt{I_{S 3}{ }^{2} \cdot Z_{n}{ }^{2}+V_{o}^{2}}$. Hence the voltage $V_{d s I}$ can drop to zero. Based on the state plane trajectory as shown in Fig. 7(c) and (14), the minimum required negative current $i_{S S_{-} v a l}$, and the extended conduction time $T_{e x}$ to achieve ZVS operation for $S_{I}$ in the half-line cycle is calculated as (16) and (17).

$$
\begin{aligned}
& i_{S 3_{-} v a l}(t)=-\sqrt{\frac{V_{i n}(t)^{2}-V_{O}^{2}}{Z_{n}^{2}}} \\
& T_{e x}(t)=\frac{\left|i_{S 3_{-} v a l}(t)\right| \cdot L_{e q}}{V_{O}}
\end{aligned}
$$

Finally, the theoretical analysis for the required negative current $i_{S 3_{-} v a l}$ and the required extended conduction time $T_{e x}$ are plotted in Fig. 8. Here the input voltage Vin is 220 Vac, and the output voltage is $100 \mathrm{Vdc}$.

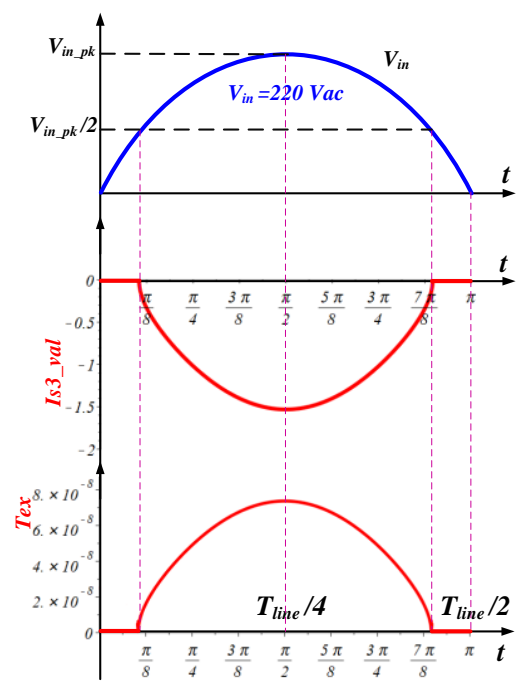

Fig. 8. Required negative current and required extended conduction time for $S_{3}$ in the positive half-line cycle.

\section{INTEGRATED INDUCTORS DESIGN}

The specification of the bridgeless Dual-SEPIC PFC is list in the Table II:

TABLE II

SPECIFICATION OF BRIDGELESS DUAL-SEPIC PFC

\begin{tabular}{cc} 
Circuit parameters & Value \\
Input voltage & $220 \mathrm{Vac}$ \\
Nominal Output voltage & $100 \mathrm{Vdc}$ \\
Input current ripple & $20 \% *$ Iin \\
Output voltage ripple & $10 \% *$ Vo \\
Power rating & $300 \mathrm{~W}$ \\
\hline
\end{tabular}

\section{A. Inductance design for the SEPIC PFC}

There are three constraints for the inductance design of the integrated inductors:

1. The ZVS turn-on in the full range of the input voltage;

2. Input inductor current ripple limitation;

3. The output inductor current ripple limitation.

For the bridgeless dual-SEPIC PFC converter, based on (7) and (8), the duty cycle can be derived:

$$
\left\{\begin{array}{l}
D_{\text {ON }}=\frac{V_{o}}{V_{i n_{-} r m s}} \sqrt{\frac{2 L_{1} \cdot L_{\text {in }}}{\left(L_{1}+L_{\text {in }}\right) R_{0} T_{s}}} \\
D_{\text {OFF }}=\sqrt{\frac{2 L_{1} \cdot L_{\text {in }}}{\left(L_{1}+L_{\text {in }}\right) R_{0} T_{s}}}
\end{array}\right.
$$

As mentioned before, $D_{O N}$ and $D_{O F F}$ are the turn-on duty cycle and turn-off duty cycle for the main switches $S_{1}$ and $S_{2}$. To make sure the output current $i_{S 3}$ can drop below zero, the sum of $D_{\text {ON }}$ and $D_{\text {OFF }}$ should always small than 1 . Thus, the first constraint can be obtained:

$$
D_{O N}+D_{O F F} \leq 1 \Rightarrow \frac{2 L_{1} \cdot L_{i n}}{\left(L_{1}+L_{i n}\right) R_{0} T_{s}} \leq \frac{\left(\sqrt{2} V_{i n_{-} r m s}\right)^{2}}{\left(\sqrt{2} V_{i n_{-} r m s}+V_{o}\right)^{2}}
$$

The relationship between $L_{i n}$ and $L_{l}$ for the inequality is shown in Fig. 9 as the red line. It can be seen that if the equivalent inductance $L_{\text {in }}$ becomes large to obtain a smaller input current ripple, then the equivalent inductance of $L_{l}$ should be limited to a smaller value. This limitation comes from the output current $i_{S 3}=i_{L i n}+i_{L I} \leqslant 0$ when $S_{3}$ turns OFF, the more negative current is needed for $i_{L 3}$ since the input current ripple becomes small.

Denoting $K_{l}$ is the peak input current ripple $\Delta i_{\text {Lin_pk }}$ over the peak input current $I_{\text {in_pek }}$, based on (7), since $\Delta i_{\text {Lin_pk }}$ $=V_{\text {in }}(t) T_{\text {on }} / L_{\text {in }}$, then $K_{l}$ can be deduced by the following equation

$$
K_{1}=\frac{\Delta i_{\text {Lin_pek }}}{\sqrt{2} \cdot I_{\text {in } r \text { rms }}}=\frac{1}{L_{i n}} \sqrt{\frac{2 L_{1} \cdot L_{i n} \cdot T_{s}}{\left(L_{1}+L_{i n}\right) P_{O}}} \sqrt{2} V_{i n_{-} r m s} \leq 0.2
$$

$K_{l}$ is determined by the output power, the inductance values, and the switching frequency. According to Table II, here, $K_{l}$ $\leqslant 0.2$ is selected, and this inequality is shown in Fig. 9 as the blue line.

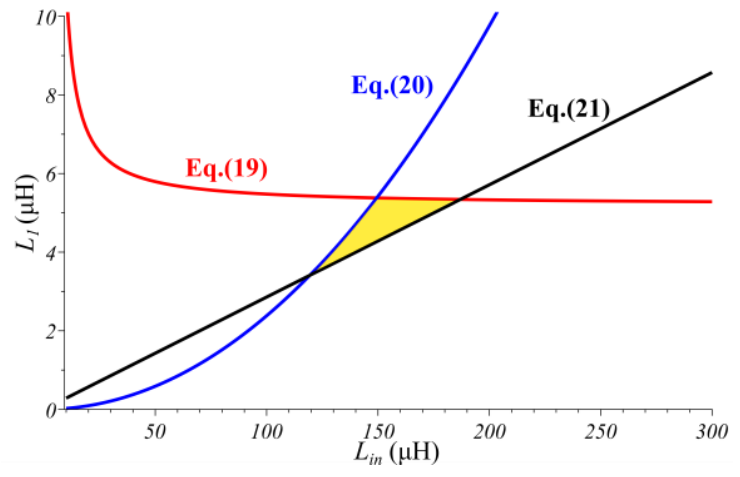

Fig. 9. Inductance design be three constraints. 


\section{IEEE POWER ELECTRONICS REGULAR PAPER}

As mention before, the voltages crossed the input inductor $L_{\text {in }}$ and output side inductor $L_{l}$ are always the same in each operation stage. Hence, the ratio of the output side inductor ripple $\Delta i_{L I}$ and the input inductor current ripple $\Delta i_{L i n}$ equals to the ratio of the inductance $L_{\text {in }}$ to $L_{l}$ shown in (21). To limit the ripple current of $L_{l}$, the inductance ratio $K_{2}$ between $L_{i n}$ and $L_{1}$ should also keep as low as possible. $K_{2}$ is selected smaller than 35, and this inequality is shown in Fig. 9 as the black line.

$$
\frac{\Delta i_{L 1}}{\Delta i_{\text {Lin }}}=\frac{L_{\text {in }}}{L_{1}} \leq K_{2}=35
$$

Based on the three constraints aforementioned in (19) (21), the available values for $L_{I}$ and $L_{i n}$ can be selected from Fig. 9 in the yellow area as bellows:

$$
\left\{\begin{array}{l}
L_{i_{-} e q}=120 \sim 190 \mu \mathrm{H} \\
L_{1_{-} e q}=4 \sim 6 \mu \mathrm{H} \\
L_{2_{-} e q}=4 \sim 6 \mu \mathrm{H}
\end{array}\right.
$$

\section{B. E-I-E core with a specified coupling coefficient}

For general three coupled inductors, the relationships among the voltage of each winding, the self-inductance, and the mutual inductance are given by the equations below, respectively:

$$
\left[\begin{array}{l}
V_{L i n} \\
V_{L 1} \\
V_{L 2}
\end{array}\right]=\left[\begin{array}{l}
L_{i n_{-} \text {self }}, \pm M_{i n \_1}, \pm M_{i n_{-} 2} \\
L_{1_{-} \text {self }}, \pm M_{1_{-i n},}, \pm M_{1_{-} 2} \\
L_{2_{-} \text {self }}, \pm M_{2_{-} i n}, \pm M_{2_{-} 1}
\end{array}\right]\left[\begin{array}{l}
\frac{d i_{\text {Lin }}}{d t} \\
\frac{d i_{L 1}}{d t} \\
\frac{d i_{L 2}}{d t}
\end{array}\right]
$$

The inductors can be coupled directly or inversely. The sign before $M$ is " + " or " - " depended on the inductors are coupled directly or inversely. $V_{L i n}, V_{L 1}$, and $V_{L 2}$ are the voltages across the three inductors, respectively. $L_{i n_{-} \text {self }}, L_{1_{-} \text {self, }}$ and $L_{2_{-} \text {self }}$ are the self-inductance value of the windings. $M$ is the mutual inductance between inductors, where $M_{l_{-} i n}=M_{i n_{-} l}, M_{2_{-} i n}=$ $M_{\text {in_ } 2}, M_{I_{-} 2}=M_{2_{-} I}$.

For the three inductors in the proposed topology, the output inductors $L_{1}$ only works in the positive half-line cycle, and $L_{2}$ only works in the negative half-line cycle. Therefore, $L_{1}$ and $L_{2}$ are directly coupled with the input inductor $L_{i n}$ separately. $L_{1}$ and $L_{2}$ need to be always decoupled from each other. In this paper, the symmetric E-I-E core geometry is selected. The magnetics structure is shown in Fig. 10. The output side inductors $L_{1}$ and $L_{2}$ are wound on the center legs of the Ecores individually. The input inductor $L_{i n}$ is wound in the middle I-core with two identical parts in series, where each part has the same number of turns. Due to the low reluctance path provided by the middle I-core, the flux induced by $L_{l}$ and $L_{2}$ will return from the middle I-core rather than the E-core. Thus, $L_{1}$ can be decoupled with $L_{2}$ by the middle I-core.

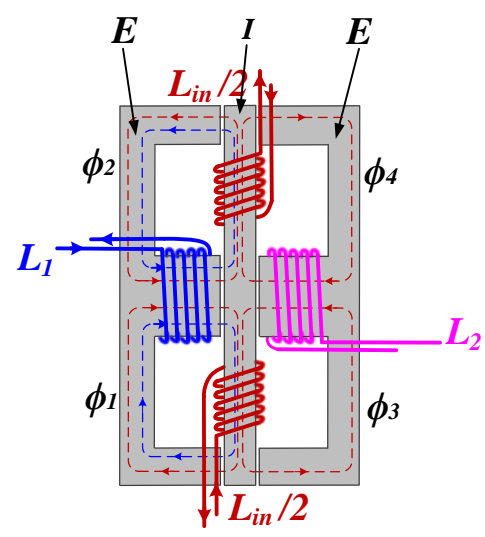

Fig. 10. Proposed E-I-E core structure for the coupled inductor.

Since $L_{1}$ is always decoupled with $L_{2}, M_{I_{-} 2}$ is equal to 0 . Taking the positive half-line cycle as an example, the identical voltages are applied to $L_{i n}$ and $L_{l}$ at all times throughout the switching period, which means $V_{L i n}$ is equal to $V_{L I}$. Since $L_{2}$ does not work at the positive line cycle, the inductor voltage is zero, $V_{L 2}=V_{C 2} \approx 0$. Then (23) can be rewritten

$$
\left\{\begin{array}{l}
V_{\text {Lin }}=L_{\text {in_self }} \frac{d i_{\text {Lin }}}{d t}+M_{i n_{-} 1} \frac{d i_{L 1}}{d t}-M_{i n_{-} 2} \frac{d i_{L 2}}{d t} \\
V_{L 1}=L_{1_{-} \text {self }} \frac{d i_{L 1}}{d t}+M_{1_{-} i n} \frac{d i_{L i n}}{d t} \\
0=L_{2_{-} \text {self }} \frac{d i_{L 2}}{d t}-M_{2_{-} \text {in }} \frac{d i_{\text {Lin }}}{d t}
\end{array}\right.
$$

Assuming $M_{\text {in_l }}=M_{\text {in_ } 2}=M, \quad L_{1_{-} \text {self }}=L_{2_{-} \text {self }}$, the equivalent inductance of each inductor can be obtained

$$
\begin{aligned}
& L_{i n_{-} e q}=\frac{L_{1_{-} \text {self }} L_{i n_{-} \text {self }}-2 M^{2}}{L_{1_{-} \text {self }}-M}=\frac{\left(1-2 k_{c}^{2}\right) L_{\text {in_self }}}{1-k_{c} \sqrt{L_{\text {in_self }} / L_{1_{-} \text {self }}}} \\
& \left\{L_{1_{-} e q}=\frac{L_{1_{-} \text {self }} L_{\text {in } \_ \text {self }}-M^{2}}{L_{\text {in_self }}-M}=\frac{\left(1-k_{c}^{2}\right) L_{1_{-} \text {self }} L_{i n_{-} \text {self }}}{L_{\text {in }}-k_{c} \sqrt{L_{1_{-} \text {self }} L_{\text {in }} \text { self }}}\right.
\end{aligned}
$$

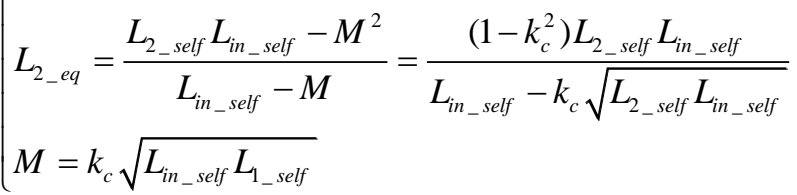

Based on (25), it shows that the equivalent inductance of the input inductor $L_{i n \_}$eq can be enlarged several times over the self-inductance $L_{i n \_s e l f}$ when the self-inductance $L_{l_{-}}$self and $L_{2}$ self are very close to the mutual inductance $M$. The required equivalent inductance of the input inductor $L_{\text {in_eq }}$ can be achieved by much smaller self-inductance $L_{\text {in_self }}$ by appropriate coupling coefficient $\left(k_{c}\right)$.

The magnetic flux flows in the proposed E-I-E core in the positive half-line cycle are shown in Fig. 11. Here $i_{L 2}$ is almost zero, only $L_{i n}$ and $L_{l}$ coupled with each other. $N_{i n}, N_{l}, N_{2}$ are the number of turns for $L_{i n}, L_{1}$, and $L_{2}$, respectively. $\Phi_{1}, \Phi_{2}$, $\Phi_{3}$, and $\Phi_{4}$ are the flux flow in four outer legs of the E-I-E core geometry, respectively. Fig. 11(a) shows an equivalent magnetic reluctance model of the proposed E-I-E core module. 


\section{IEEE POWER ELECTRONICS REGULAR PAPER}

Where $R_{l l}$ and $R_{l 2}$ are the reluctance of E-core, $R_{l i n}$ is the reluctance of I-core, here $R_{l l}=R_{l i n}$. $R_{g 1}$ and $R_{g 2}$ represent the reluctance of the air gap between the I-core, and two E-cores, The air-gap of $g_{1}$ is also identical to $g_{2}$, i.e., $R_{g}=R_{g 1}=R_{g 2}$. By defining $R_{l}=R_{l 1}+R_{l 2}+R_{g}, \quad R_{2}=\left(R_{l 2}+R_{g}\right) / 2, \quad$ the magnetic reluctance model can be simplified to Fig. 11(b).

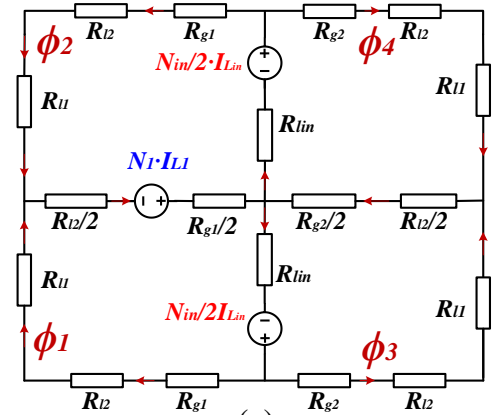

(a)

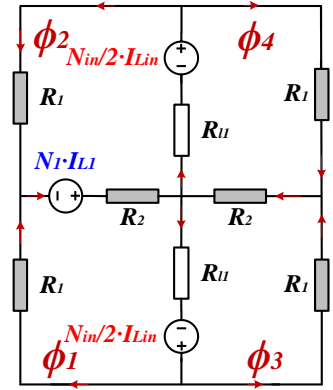

(b)
Fig. 11. The magnetic reluctance model of the E-I-E core. (a)The original model. (b) The simplified model.

Based on the equivalent magnetic reluctance model, four reluctance equations in each sub-loop can be obtained:

$$
\left\{\begin{array}{l}
\frac{N_{i n} i_{\text {Lin }}}{2}+N_{1} i_{L 1}=\Phi_{1} \cdot R_{1}+\left(\Phi_{1}+\Phi_{2}\right) \cdot R_{2}+\left(\Phi_{1}+\Phi_{3}\right) R_{l 1} \\
\frac{N_{i n} i_{\text {Lin }}}{2}+N_{2} i_{L 2}=\Phi_{2} \cdot R_{1}+\left(\Phi_{1}+\Phi_{2}\right) \cdot R_{2}+\left(\Phi_{2}+\Phi_{4}\right) R_{l 1} \\
\frac{N_{i n} i_{\text {Lin }}}{2}=\Phi_{3} \cdot R_{1}+\left(\Phi_{3}+\Phi_{4}\right) \cdot R_{2}+\left(\Phi_{1}+\Phi_{3}\right) R_{l 1} \\
\frac{N_{i n} i_{\text {Lin }}}{2}=\Phi_{4} \cdot R_{1}+\left(\Phi_{3}+\Phi_{4}\right) \cdot R_{2}+\left(\Phi_{2}+\Phi_{4}\right) R_{l 1}
\end{array}\right.
$$

Since the flux $\Phi_{1}$ is identical to $\Phi_{2}$, and $\Phi_{3}$ is identical to $\Phi_{4}$ because of the symmetrical core structure and windings, then (26) can be simplified into two equations:

$$
\left\{\begin{array}{l}
\frac{N_{i n} i_{\text {Lin }}}{2}+N_{1} i_{L 1}=\Phi_{1} \cdot R_{1}+\Phi_{1} \cdot 2 \cdot R_{2}+\left(\Phi_{1}+\Phi_{3}\right) R_{l 1} \\
\frac{N_{\text {in }} i_{\text {Lin }}}{2}=\Phi_{3} \cdot R_{1}+\Phi_{3} \cdot 2 \cdot R_{2}+\left(\Phi_{1}+\Phi_{3}\right) R_{l 1}
\end{array}\right.
$$

Solving (27), then the flux in each loop is obtained:

$$
\left\{\begin{array}{l}
\Phi_{1}=\Phi_{2}=\frac{\left(R_{1}+2 R_{2}\right) N_{i n} i_{L i n}+4 R_{1} N_{l} i_{L l}}{2\left(R_{1}+2 R_{2}\right)\left(2 R_{l}+R_{l l}\right)} \\
\Phi_{3}=\Phi_{4}=\frac{\left(R_{1}+2 R_{2}\right) N_{i n} i_{L i n}-2 R_{l l} N_{l} i_{L l}}{2\left(R_{1}+2 R_{2}\right)\left(2 R_{l}+R_{l l}\right)}
\end{array}\right.
$$

The total flux flows through the winding $L_{l}$ is $\Phi_{1}+\Phi_{2}=2 \Phi_{l}$, and the total flux flows through $L_{i n}$ is $\Phi_{1}+\Phi_{2}+\Phi_{3}+\Phi_{4}=2\left(\Phi_{1}+\Phi_{3}\right)$. Taking the partial derivative of the total flux in each winding:

$$
\left\{\begin{array}{l}
V_{L 1}=N_{1} \cdot \frac{d\left(\Phi_{1}+\Phi_{2}\right)}{d t}=\frac{4 N_{1}^{2} \cdot R_{1}}{\Delta} \cdot \frac{d i_{L 1}}{d t}+\frac{N_{\text {in }} \cdot N_{1}}{2 R_{l}+R_{l l}} \cdot \frac{d i_{\text {Lin }}}{d t} \\
V_{\text {Lin }}=N_{\text {in }} \cdot \frac{d\left(\Phi_{1}+\Phi_{3}\right)}{d t}=\frac{N_{\text {in }}^{2}}{2 R_{l}+R_{l l}} \cdot \frac{d i_{\text {Lin }}}{d t}+\frac{N_{\text {in }} \cdot N_{1}}{2 R_{l}+R_{l l}} \cdot \frac{d i_{L 1}}{d t}
\end{array}\right.
$$

The equation (29) can be rewritten

$$
\left[\begin{array}{l}
V_{L 1} \\
V_{L i n}
\end{array}\right]=\left[\begin{array}{cc}
\frac{4 N_{1}^{2} \cdot R_{1}}{\Delta} & \frac{N_{i n} \cdot N_{1}}{2 R_{1}+R_{l 1}} \\
\frac{N_{i n} \cdot N_{1}}{2 R_{1}+R_{l l}} & \frac{N_{i n}^{2}}{2 R_{1}+R_{l l}}
\end{array}\right]\left[\begin{array}{l}
\frac{d i_{L 1}}{d t} \\
\frac{d i_{\text {Lin }}}{d t}
\end{array}\right]=\left[\begin{array}{cc}
L_{1_{1} \text { self }} & M \\
M & L_{\text {in_self }}
\end{array}\right]\left[\begin{array}{l}
\frac{d i_{L 1}}{d t} \\
\frac{d i_{L i n}}{d t}
\end{array}\right]
$$

Here $\Delta=\left(2 R_{l}+R_{l l}\right)\left(R_{l}+2 R_{2}\right)$, then self-inductances and mutual inductances can be obtained:

$$
\left\{\begin{array}{l}
L_{1_{-} \text {self }}=\frac{4 N_{1}^{2} \cdot R_{1}}{\left(2 R_{1}+R_{l l}\right)\left(R_{1}+2 R_{2}\right)} \\
L_{\text {in_self }}=\frac{N_{i n}^{2}}{2 R_{1}+R_{l 1}} \\
M=\frac{N_{i n} \cdot N_{1}}{2 R_{1}+R_{l l}}
\end{array}\right.
$$

Finally, the theoretical coupling coefficient can be derived:

$$
k_{C}=\frac{M}{\sqrt{L_{1_{-} \text {self }} \cdot L_{\text {in_self }}}}=\sqrt{\frac{R_{I}+2 R_{2}}{4 R_{I}}} \approx \sqrt{\frac{1}{2}}=0.707
$$

Here it can be seen that the coupling coefficient is related to the core structure, the air-gap, and the material of the magnetic core. $R_{g}$ is much bigger than $R_{l l}$ and $R_{l 2}$ due to the air-gaps between the E-core and I-core. Hence, the theoretically calculated value of the coupling coefficient is around 0.7. It has also been verified in the 2D finite-element analysis (FEA) simulation.

\section{HARDWARE IMPLEMENTATION}

A $300 \mathrm{~W}$ GaN-based MHz bridgeless Dual-SEPIC PFC prototype is built to verify the ZVS control method with the integrated E-I-E inductors. The integrated inductor design for the Dual-SEPIC PFC, and control scheme are described as follows.

\section{A. Integrated inductor design}

Ferrite material with $3 \mathrm{~F} 36$ is selected since it is suitable for high frequency from $300 \mathrm{kHz}$ to $1 \mathrm{MHz}$. The detailed parameters of the integrated E-I-E core are listed in Table III.

TABLE III

PARAMETERS OF E-I-E CORE

\begin{tabular}{cc}
\hline \hline Circuit parameters & Value \\
\hline Ferrite core material & $3 \mathrm{~F} 36(300 \mathrm{kHz}$ to $1 \mathrm{MHz})$ \\
Initial permeability $\left(\mu_{0}\right)$ & 1600 \\
E-core size & E43/10/28 \\
I-core size & PLT43/28/4.1 \\
\hline \hline
\end{tabular}

Defining $K_{L i n}$, and $K_{L l}$ are the ratios of the equivalent inductance over the self-inductance for the input inductor $L_{i n}$ and the output side inductor $L_{l}$, respectively. According to (25) and (31), $K_{L i n}$, and $K_{L l}$ can be obtained 


\section{IEEE POWER ELECTRONICS REGULAR PAPER}

$$
\begin{gathered}
K_{L 1}=\frac{L_{1_{-} e q}}{L_{1_{-} \text {self }}}=\frac{1-k_{c}^{2}}{1-k_{c} \sqrt{L_{1_{-} \text {self }} / L_{\text {in_self }}}}=\frac{1-k_{c}^{2}}{1-\sqrt{2} k_{c} \frac{N_{1}}{N_{\text {in }}}} \\
K_{\text {Lin }}=\frac{L_{\text {in_eq }}}{L_{\text {in } \_ \text {self }}}=\frac{1-2 k_{c}^{2}}{1-k_{c} \sqrt{L_{\text {in_self }} / L_{1_{-} \text {self }}}}=\frac{1-2 k_{c}^{2}}{1-\frac{1}{\sqrt{2}} k_{c} \frac{N_{\text {in }}}{N_{1}}}
\end{gathered}
$$

It can be seen that $K_{L i n}$ and $K_{L 1}$ are determined by the number of winding turns and coupling coefficient $k_{c}$. According to the equivalent inductance requirement based on (22) and the flux saturation limitation, here, $N_{\text {in }}=12, N_{1}=N_{2}$ $=5$ are selected. The relationship between $K_{L i n}, K_{L l}$ with the coupling coefficient $k_{c}$ is shown in Fig. 12. Fig. 12(a) shows that the equivalent inductance $L_{i n \_} e q$ can be enlarged several times to self-inductance $L_{i n \_s e l f}$. On the other side, the ratio $K_{L 1}$ for $L_{1}$ is around 1, as shown in Fig. 12(b), meaning that the self-inductance $L_{I_{-} \text {self }}$ is almost equal to the inductance $L_{I_{-} e q}$.

As shown in Fig. 12(a), when the coupling coefficient $k_{c}$ is large than 0.59 , the value of equivalent inductance $L_{i n \_e q}$ is negative, which means the rate of the flux change and the rate of the current change, are negative as shown in Fig. 13 in the dashed line. To obtain the same negative current $I_{S 3_{-} v a l}$ when $S_{3}$ is OFF to achieve ZVS for $S_{1}$, more current rippled will be introduced for $L_{l}$ when $k_{c}>0.59$. Therefore, to minimize the inductor ripple, the coupling coefficient should be designed to less than 0.59 .

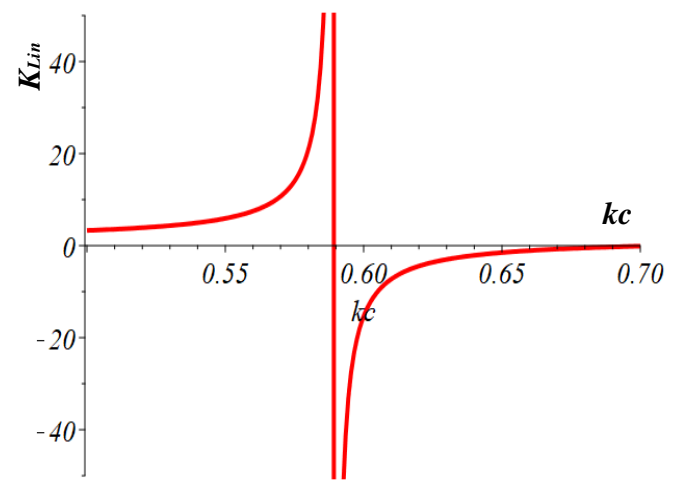

(a)

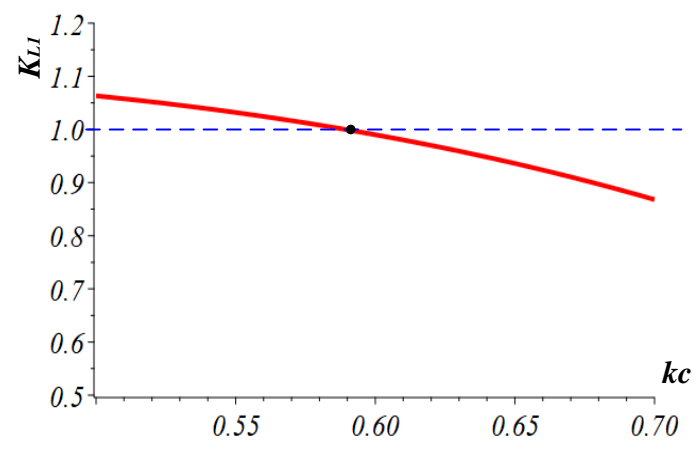

(b)

Fig. 12. Relationship between $k_{c}$ and ratios of equivalent-inductance over self-inductance. (a) $K_{L i n}$ (b) $K_{L I}$

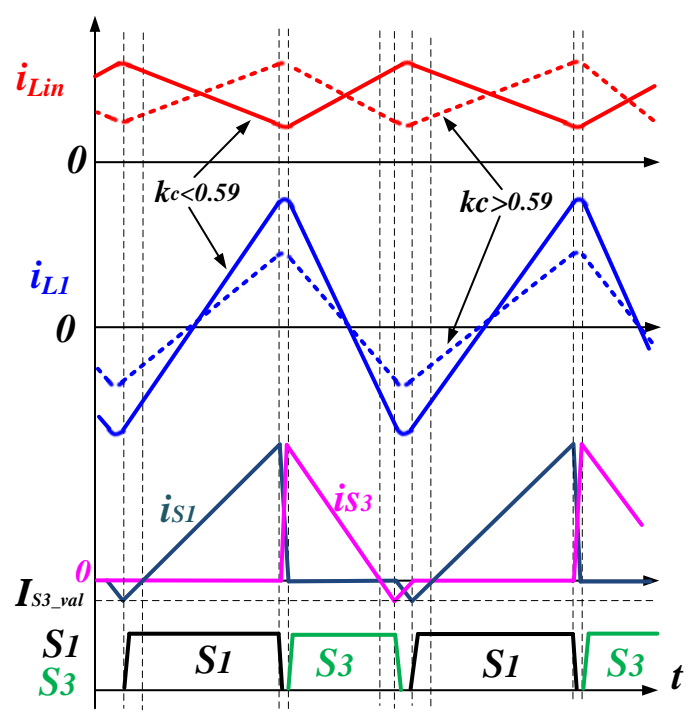

Fig. 13. Current waveform when $k_{c}$ is large than 0.59.

Since the self-inductance $L_{\text {in_self }}$ is around $15 \mu \mathrm{H}$ and $L_{I_{-} \text {self }}$ is around $5 \mu \mathrm{H}$, to satisfy the equivalent inductance requirement $(22)$, the ratio $K_{\text {Lin }}=L_{\text {in_eq }} / L_{\text {in__self }}$ is designed between 8 to 10. Thus, according to Fig. 14, the coupling coefficient $k_{c}$ ranges from 0.562 to 0.568 .

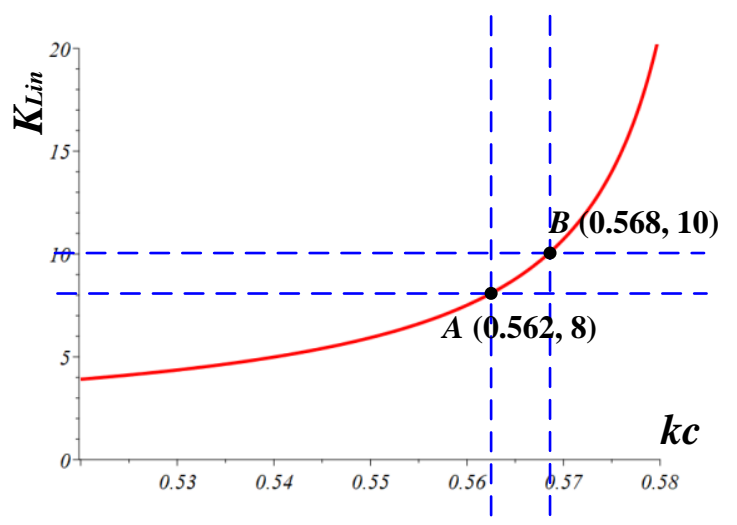

Fig. 14. Relationship between $k_{c}$ and $K_{\text {Lin }}$

To verify the equivalent magnetic reluctance model and select the air-gap for the E-I-E integrated inductors, 2D finiteelement analysis (FEA) simulation has been conducted. As shown in Fig. 15(a), the flux is symmetrical in the E-I-E core. Fig. 15(b) shows the integrated inductors with four windings for the E-I-E core. The practical value of the coupling coefficient has been obtained based on the decoupled $\mathrm{T}$ model of the coupled inductor for the proposed E-I-E core geometry.

Finally, the relationship between the air-gap and coupling coefficient both for FEA simulation and practical test are shown in Fig. 16. It can be seen that the coupling coefficient $k_{c}$ is decreased when the length of the air-gap increases. Both of them are smaller than the theoretical analysis value 0.7 due to the leakage flux and fringing effect [41][42]. 


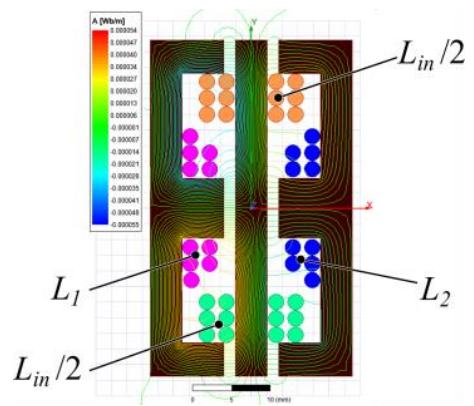

(a)

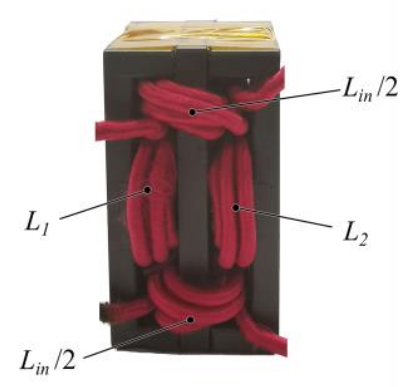

(b)

Fig. 15. The proposed E-I-E core. (a) Flux distribution for 2D-FAE simulation. (b) the practical E-I-E core structure.

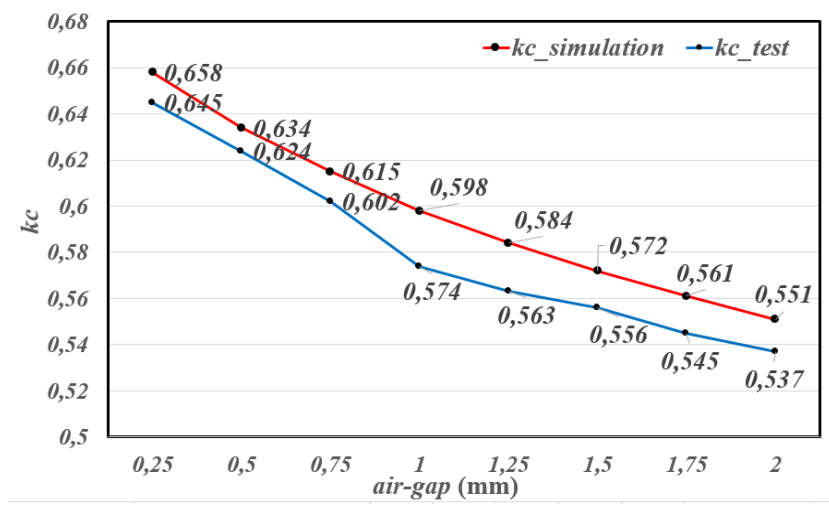

Fig. 16. Coupling coefficient value with different air-gap under 2D FEA simulation and practical test.

According to the aforementioned analysis, the air-gap $g_{1}=g_{2}=1.3 \mathrm{~mm}$ is selected for the integrated E-I-E core inductors. According to $L_{e q}=V_{i n} T_{o n} / \Delta i_{L}$, the practice equivalent inductance can be obtained by the testing inductor current waveform. The self-inductances are directly obtained by the precision impedance analyzer Agilent 4294A. Finally, Table IV illustrates the actual inductance of the E-I-E integrated inductors.

Fig.17 shows the size comparison between the proposed E-I-E integrated inductors and the conventional discrete inductors. Here it shows that the integrated inductors can make the magnetic components more compact and reduce the volume of the inductor size.

TABLE IV

DESIGN INDUCTANCE OF THE INTEGRATED INDUCTOR

\begin{tabular}{ccc}
\hline \hline & E-I-E core parameters & Value $(\mu \mathrm{H})$ \\
& $L_{\text {in_self }}$ & 14.14 \\
Self-inductance & $L_{1 \_ \text {self }}$ & 5.18 \\
& $L_{2 \_ \text {self }}$ & 5.30 \\
& $L_{\text {in_eq }}$ & 140.27 \\
\multirow{3}{*}{ Equivalent inductance } & $L_{1 \_ \text {eq }}$ & 5.81 \\
& $L_{2 \_e q}$ & 5.63 \\
Mutual inductance & $M_{1 \_ \text {in }}$ & 5.6 \\
& $M_{2 \_ \text {in }}$ & 5.4 \\
\hline \hline
\end{tabular}

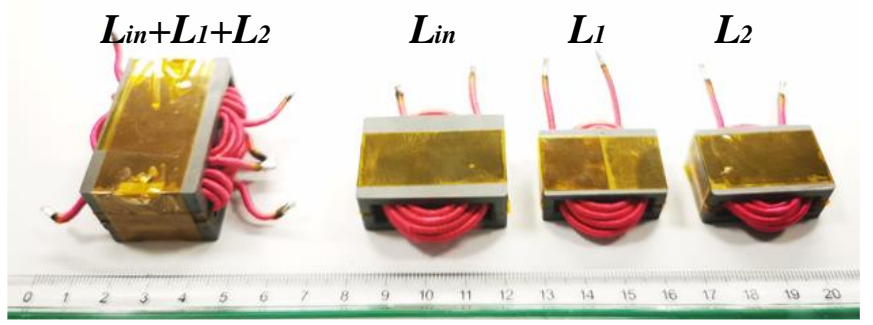

Fig. 17. Size comparison between the integrated inductors and three isolated inductors

\section{B. Control scheme}

Fig. 18 shows the simplified control diagram with the MCUbased digital controller for the bridgeless Dual-SEPIC PFC. The voltage-mode control method is selected since it does not require a high-speed current sensor and is easy to implement than the current-mode control. To attenuate the double line voltage ripple on the DC bus, the bandwidth of the voltage loop is designed around $10 \mathrm{~Hz}$. The difference between the output voltage reference $V_{o_{-} r e f}$ and the real output voltage $V_{o_{-} \text {real }}$ is sent to the voltage PI controller. The PI controller determines the ON-time $\left(T_{o n}\right)$ of the main switches $S_{1}$ and $S_{2}$ in different half-line cycles.

The turn-off instant for the synchronous switches $S_{3}$ and $S_{4}$ are triggered by the zero current detection (ZCD) signal. The ZCD signal is obtained by the shunt resistor $R_{Z C D}$ placed before the output capacitor. After the ZCD signal is sent to the digital controller, the extended conduction time $T_{e x}$ for $S_{3}$ and $S_{4}$ is added based on (16) and (17) to achieve the required negative current $i_{S S_{-} \text {val. }}$. The gate driver signals for $S_{2}$ and $S_{4}$ in the positive half-line cycle are determined by the input voltage and threshold voltage $V_{t h}$.

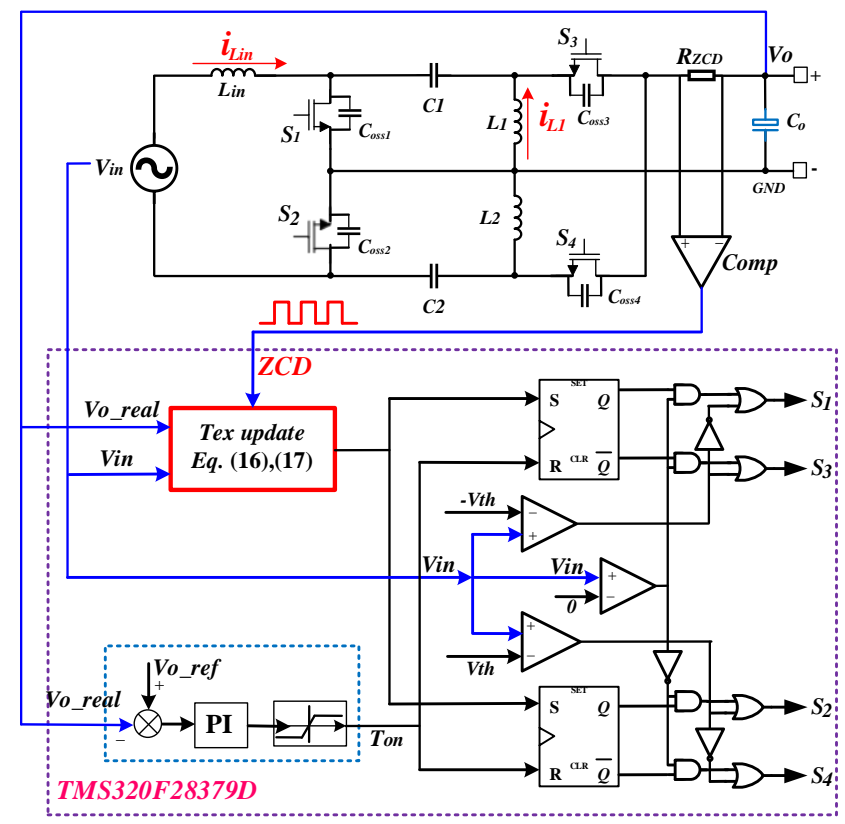

Fig. 18. The simplified control diagram for the SEPIC PFC. 


\section{IEEE POWER ELECTRONICS REGULAR PAPER}

\section{EXPERIMENTAL SETUP AND MEASUREMENT}

\section{A. Experimental prototype}

Fig. 19 shows the photo of the $300 \mathrm{~W}$ prototype converter. The size of this prototype is $14.7 \mathrm{~cm} \times 5.3 \mathrm{~cm} \times 2.8 \mathrm{~cm}$; the parameters of the key components are listed in Table V. The intermediate capacitor is $940 \mathrm{nF}$ with two film capacitors paralleled. The DC-link bulky capacitors are $1320 \mathrm{uF}$ with four electrolytic capacitors in parallel. The film capacitor has been used for the intermediate capacitors $C_{1}$ and $C_{2}$. But the size of the intermediate capacitors can further be reduced by using few high voltage ceramic capacitors in parallel ( such as CKC33C224JCGACTU, C0G, $500 \mathrm{~V}, 0.22 \mathrm{uF}$ ) since the capacitance is not very high.

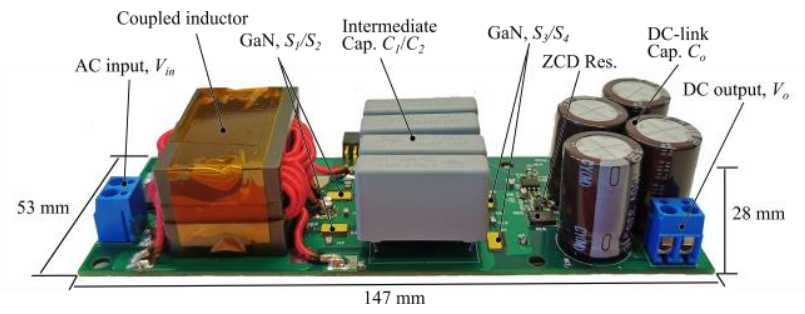

Fig. 19. Prototype of the proposed SEPIC PFC.

TABLE V

PARAMETERS OF KEY COMPONENTS

\begin{tabular}{|c|c|}
\hline Circuit parameters & Value \\
\hline$S_{1} \sim S_{4}$ & GS66508T, $650 \mathrm{~V}, 50 \mathrm{~m} \Omega$ \\
\hline Isolate driver & SI8271AB-IS \\
\hline Digital isolator & ADUM1100 \\
\hline Optically Isolated Amplifiers & ACPL-C87 \\
\hline$C_{l} / C_{2}$, Film Capacitor & MKP385E44740JKI2B0, $4 * 470 \mathrm{nF}$ \\
\hline Output electrolytic capacitor & UCY2C331MHD6, 4*330 uF \\
\hline Shunt resistor for ZCD circuit & WSHM2818R0150FEA, $15 \mathrm{~m} \Omega$ \\
\hline Comparator for ZCD circuit & LMV7219 \\
\hline Switching frequency & $400 \mathrm{kHz} 1 \mathrm{MHz}$ \\
\hline Digital controller & TMS320F28379D, $200 \mathrm{MHz}$ \\
\hline
\end{tabular}

\section{B. Measurement}

Fig. 20(a) and Fig. 20(b) show the two different situations for DCM conventional SEPIC PFC with the output diode. After the current of the diode $i_{D o}$ decreases to zero, the resonance happened between $V_{d s}$ and $i_{D o}$. In Fig. 20(a), when $V_{i n} \leq V_{O}$, the ZVS operation for $S_{l}$ can be achieved since $V_{d s l}$ can resonate to zero. However, when $V_{i n}>V_{O}$, only partial ZVS turn-on can be achieved at the valley switching, as shown in Fig. 20(b). Fig. 20(c) shows the waveform of ZVS for the modified SEPIC PFC with an extended conduction time $T_{e x}$ added for the synchronous GaNFETs $S_{3}$. The negative current $i_{S 3}$ transfer to the main switch $S_{l}$ to help achieve ZVS for $S_{I}$ after the $S_{3}$ turns OFF. The drain-source voltage $V_{d s l}$ is discharged to zero before the main switch $S_{1}$ turns ON, thus the ZVS is guaranteed in the full range of the input voltage.

Fig. 21 shows the waveform of the drain-source voltage $V_{d s}$, $V_{d s 3}$, and the gate driver signal in one switching cycle in the positive half-line cycle. Here it can be seen that the ZVS for both the main switch and synchronous switch is achieved.

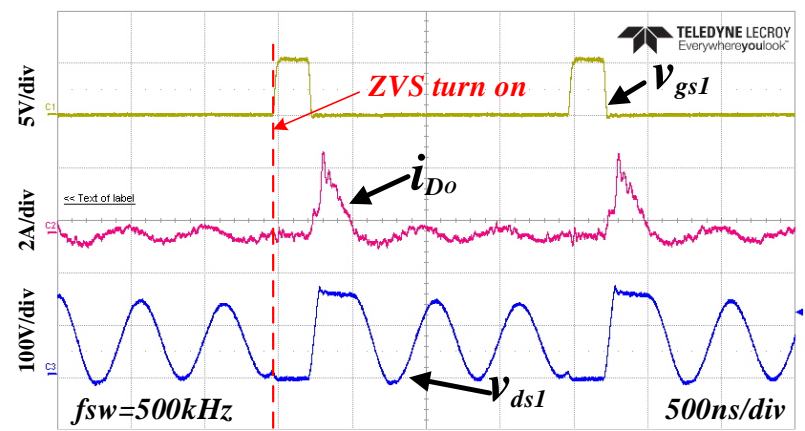

(a)

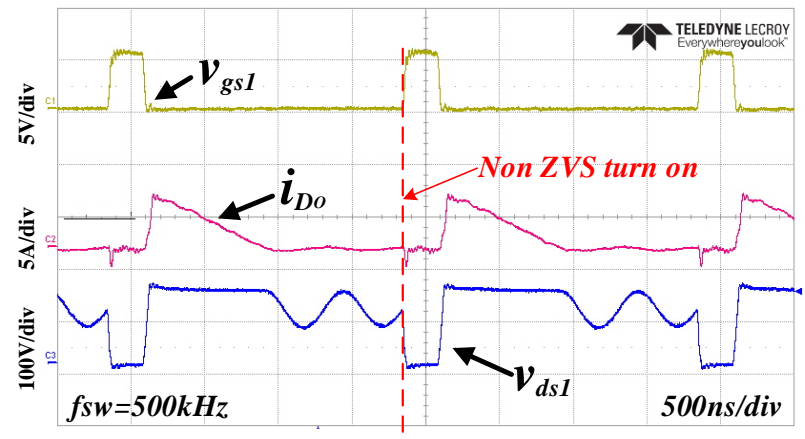

(b)

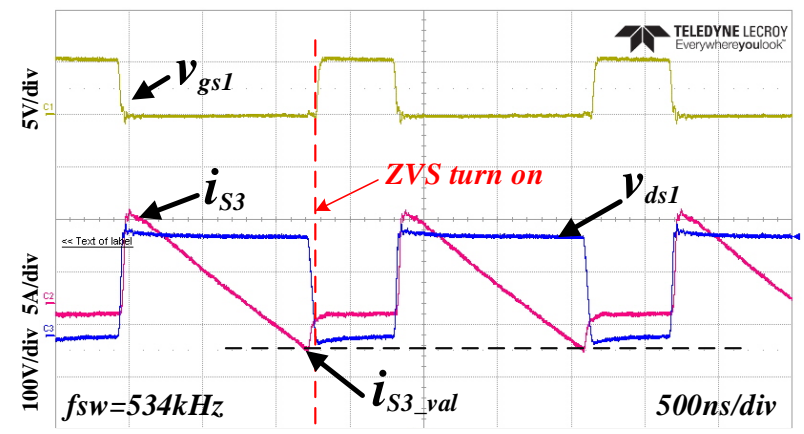

(c)

Fig. 20. waveform for ZVS turn-on and Non ZVS turn-on. (a) ZVS turnon for conventional SEPIC PFC with synchronous diode when Vin $\leqslant V o$

(b ) Non ZVS turn-on for conventional SEPIC PFC with synchronous diode when Vin $>$ Vo. (c) ZVS turn-on for the modified SEPIC PFC.

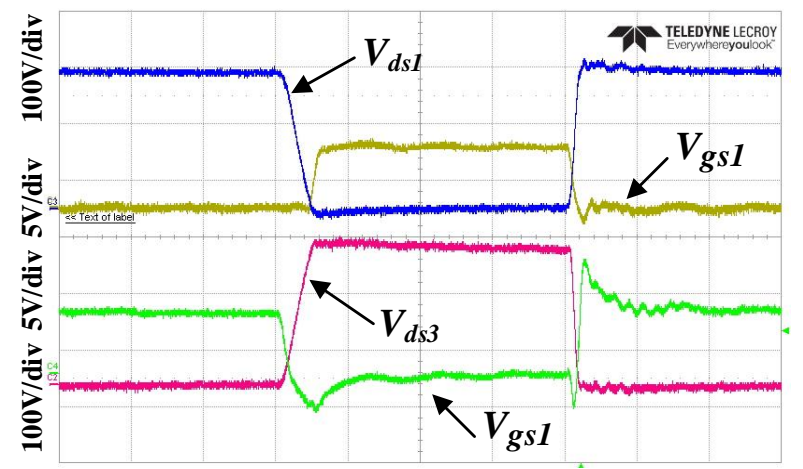

Fig. 21. The waveform of ZVS turn on for $S_{1}$ and $S_{3}$ 


\section{IEEE POWER ELECTRONICS REGULAR PAPER}

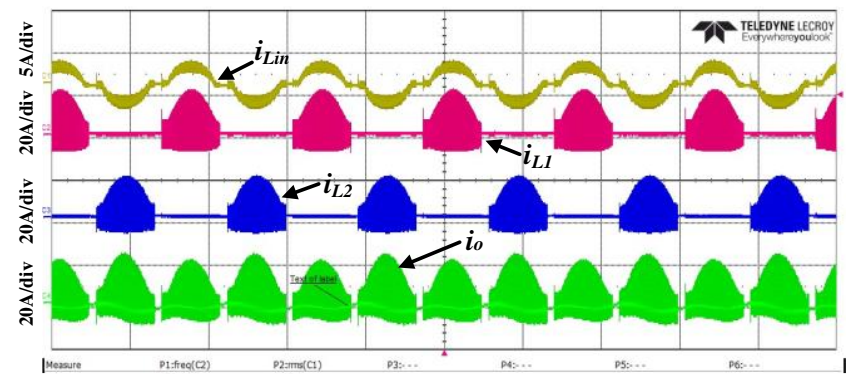

Fig. 22. waveform of inductor current and input voltage

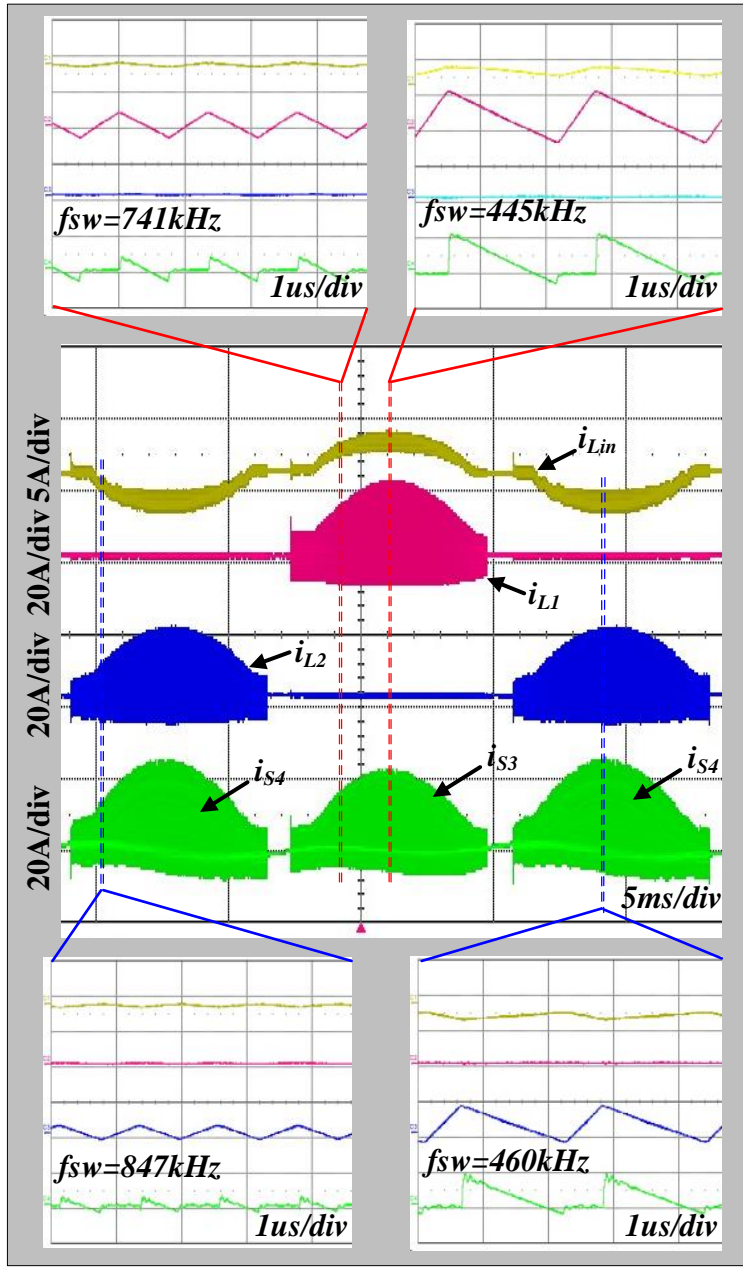

Fig. 23. waveform of inductor current and input voltage

Fig. 22 shows the waveform of three inductor currents $i_{\text {Lin }}$, $i_{L l}, i_{L 2}$, and the output current before the DC bulk capacitors $i_{o}$ for the bridgeless Dual-SEPIC PFC. The output current $i_{o}$ is equal to the sum of the three inductor currents in the whole line cycle. It can be seen that the input current $i_{\text {Lin }}$ is working in CCM mode, and the input current ripple is much smaller than the output current ripple.

Fig. 23 shows the detailed waveform of the three inductor currents in different switching period with variable switching frequencies. The top two sub-figures show the switching cycle in the positive half-line cycle. Here it can be seen that the output side inductor current $i_{L 2}$ is almost 0 . The output current $i_{o}$ is equal to $i_{S 3}$, which is the sum of $i_{L i n}$ and $i_{L I}$. Identically the bottom two sub-figures show the inductor currents in the negative half-line cycle. Here, the inductor current $i_{L l}$ is almost 0 , and $i_{o}$ is equal to the sum of $i_{\text {Lin }}$ and $i_{L 2}$. The switching frequency of the SEPIC PFC ranges from $400 \mathrm{kHz}$ in the middle half-line cycle to $1 \mathrm{MHz}$ in the crossing section of the line-cycle.

Fig. 24 and Fig. 25 show the experimental results for the transient performance of the proposed integrated inductors. The output voltage reference is changed from $60 \mathrm{Vdc}$ to $100 \mathrm{Vdc}$. Here it shows the integrated inductors work well under the transient change without any overshoot or undershoot.

Fig. 26 shows the testing waveform of the input current, input voltage, and DC-link voltage. The DC-link voltage is maintained at around $100 \mathrm{Vdc}$. Fig. 27 shows that the voltage of the intermediate capacitor $V_{C 1}$ and $V_{C 2}$ equal to the input voltage $V_{i n}$ in the positive half-line cycle and negative half-line cycle, respectively.

Fig.28 shows the input current THD of the bridgeless DualSEPIC PFC. Fig.29 shows the input current of each harmonic order for the bridgeless Dual-SEPIC PFC is under the limitation of the international standard EN61000-3-2 Class-A. Due to the negative current in the switching cycle and the no power transfer mode near the zero-crossing input voltage, some distorted input current has happened around the zero-crossing section of the input voltage [39],[44].

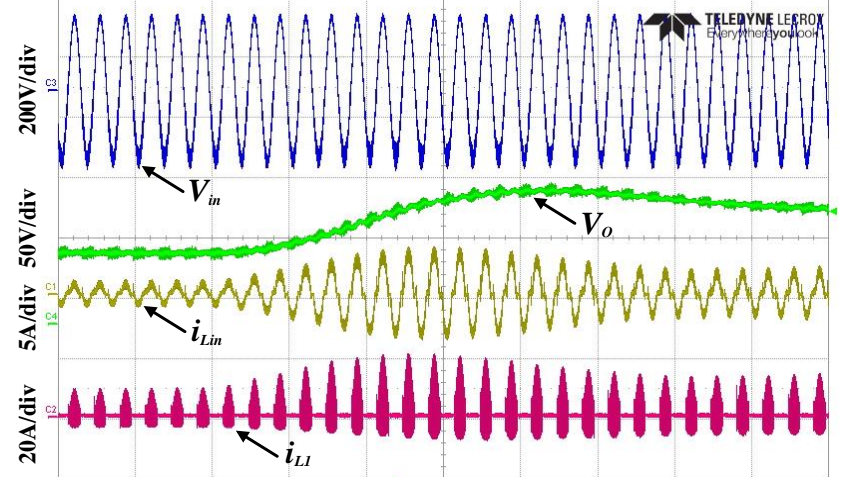

Fig. 24. dynamic response from Vo_ref $=60 \mathrm{Vdc}$ to $100 \mathrm{Vdc}$

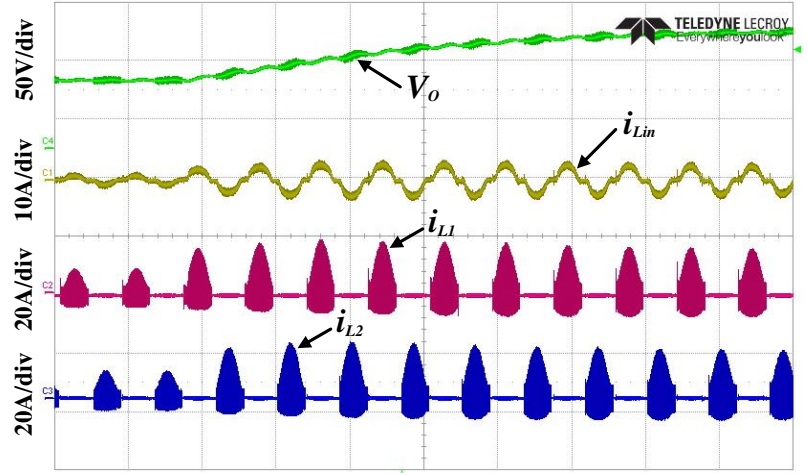

Fig. 25. Three inductor current waveforms of the integrated inductors under dynamic response 


\section{IEEE POWER ELECTRONICS REGULAR PAPER}

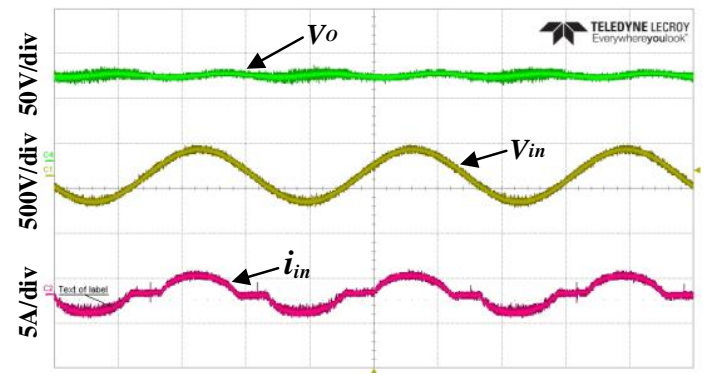

Fig. 26. waveform of input current, input voltage, and DC-link voltage

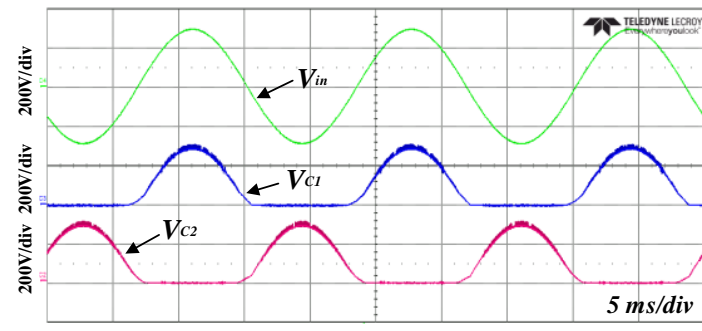

Fig. 27. the waveform of input volage $V_{i n}$, intermediate capacitors voltage $V_{C l}, V_{C 2}$.

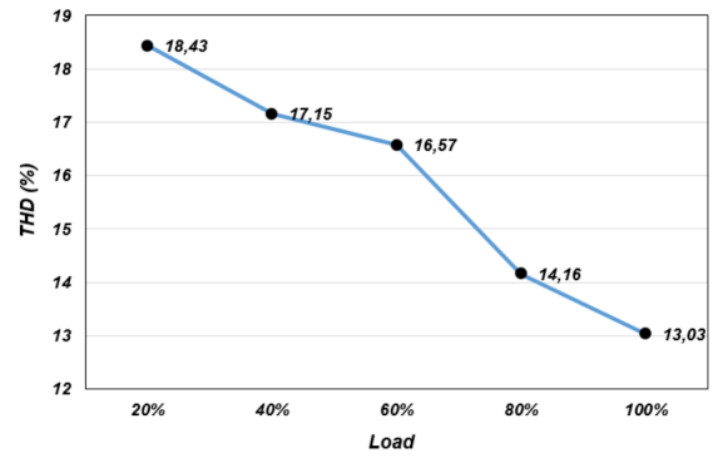

Fig. 28. Measured THD of the SEPIC PFC $\left(V_{i n}=220 \mathrm{Vac}\right)$
The system efficiency (including the DC-link bulky capacitors) of the porotype from $10 \%$ to $100 \%$ of full load under the $V_{i n}=220 \mathrm{Vac}, V_{o}=100 \mathrm{Vdc}$, is shown in Fig. 30 . The peak efficiency is $97 \%$ under full load.

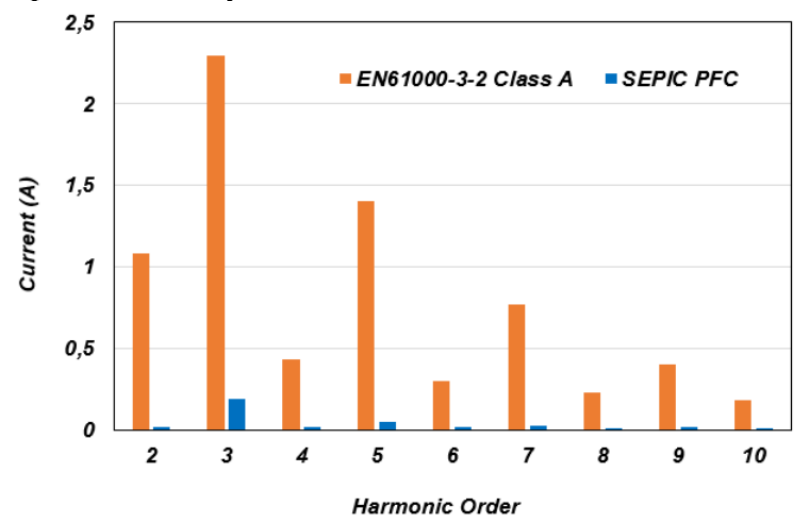

Fig. 29. Harmonics of Dual SEPIC PFC and Class-A equipment harmonic current limit standard

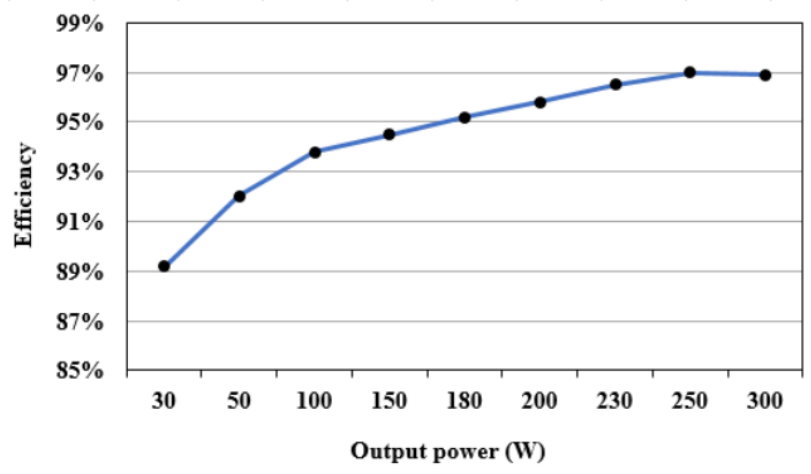

Fig. 30. Measured efficiency curve of the SEPIC PFC prototype

Table VI lists the comparison of the state-of-the-art SEPIC PFC with the modified SEPIC PFC. It can be seen that the

TABLE VI

Comparison of different SEPIC PFC

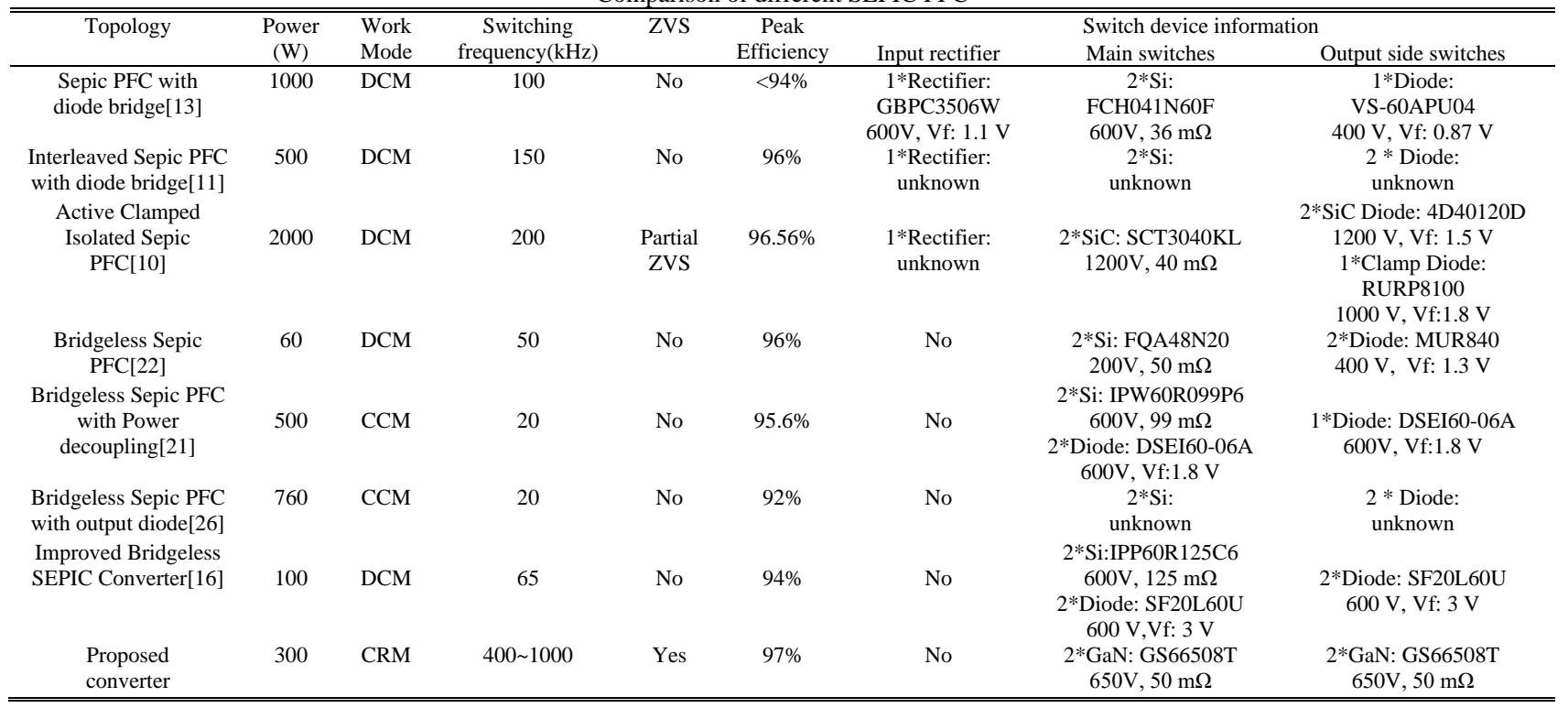




\section{IEEE POWER ELECTRONICS REGULAR PAPER}

GaN-based MHz Dual-SEPIC PFC developed by the author's group is the only one that can achieve the ZVS in the full range of the input voltage. It achieves the highest peak efficiency in a high switching frequency.

\section{CONCLUSION}

This paper presents a bridgeless GaN-based Dual-SEPIC PFC with ZVS operation for the application of a step-down AC-DC converter. The input current is working in CCM mode, and the sum of the input current and output current is working in CRM mode. To achieve the ZVS operation for the main switch, the extra negative current is provided by adding the extended conduction time for the synchronous switch after the current of the synchronous switch decrease to zero. Moreover, The E-I-E integrated inductors have been proposed for the bridgeless Dual-SEPIC PFC. All the inductors, including one input inductor and two output inductors, have been integrated into the E-I-E core, reducing the total ferrite volume and making the converter more compact. The inductance design and magnetic modeling for the coupled inductor have been analyzed. With a carefully designed coupling coefficient, the equivalent input inductance can be implemented with a much smaller number of winding turns. A 300W GaN-based MHz bridgeless Dual-SEPIC PFC with the integrated inductors is developed to verify the theoretical analysis and design. The experimental results show that fullrange ZVS is realized, and the peak efficiency is $97 \%$.

\section{REFERENCES}

[1] M. M. Jovanovic and Y. Jang, "State-of-the-art, single-phase, active power-factor-correction techniques for high-power applications- An overview," IEEE Trans. Ind. Electron., vol. 52, no. 3, pp. 701-708, Jun. 2005.

[2] J. A. Garcia, R. Cobos, P. Prieto and J. Uceda Alou, "Single phase power factor correction: A survey", IEEE Trans. Power Electron., vol. 18, no. 3, pp. 749-755, May 2003.

[3] Limits for harmonic current emissions (equipment input current $\leq 16 \mathrm{~A}$ per phase), IEC Standard 61000-3-2, Ed. 3.2, 2009.

[4] L. Huber, Y. Jang, and M. M. Jovanovic, "Performance evaluation of bridgeless PFC boost rectifiers," IEEE Trans. Power Electron., vol. 23, no. 3, pp. 1381-1390, May 2008.

[5] K. Raggl, T. Nussbaumer, G. Doerig, J. Biela, and J. W. Kolar, "Comprehensive design and optimization of a high-power-density single-phase boost PFC," IEEE Trans. Ind. Electron., vol. 56, no. 7, pp. 2574-2587, Jul. 2009.

[6] Marxgut, C.; Krismer, F.; Bortis, D.; Kolar, J.W., "Ultraflat Interleaved Triangular Current Mode (TCM) Single-Phase PFC Rectifier," Power Electronics, IEEE Transactions on, vol.29, no.2, pp.873,882, Feb. 2014.

[7] F. C. Lee, Q. Li, Z. Liu, Y. Yang, C. Fei, and M. Mu, "Application of GaN devices for $1 \mathrm{~kW}$ server power supply with integrated magnetics," CPSS Trans. Power Electron. Appl., vol. 1, no. 1, pp. 3-12, Dec. 2016.

[8] Q. Huang, A. Q. Huang, "Review of GaN Totem-Pole Bridgeless PFC," in CPSS Transactions on Power Electronics and Applications, vol. 2, no. 3, 2017.

[9] Lyrio Simonetti, D.S.; Sebastian, J.; Uceda, J., "The discontinuous conduction mode Sepic and Cuk power factor preregulators: analysis and design," Industrial Electronics, IEEE Transactions on, vol.44, no.5, pp.630,637, Oct 1997.

[10] D. Wu, R. Ayyanar, M. Sondharangalla and T. Meyers, "HighPerformance Active-Clamped Isolated SEPIC PFC Converter With SiC
Devices and Lossless Diode Clamp," in IEEE Journal of Emerging and Selected Topics in Power Electronics, vol. 8, no. 1, pp. 567-577, March 2020.

[11] Chuan Shi, Alireza Khaligh, Haoyu Wang, "Interleaved SEPIC Power Factor Preregulator Using Coupled Inductors In Discontinuous Conduction Mode With Wide Output Voltage," Industry Applications IEEE Transactions on, vol. 52, no. 4, pp. 3461-3471, 2016.

[12] H. Wang and A. Khaligh, "Interleaved SEPIC PFC converter using coupled inductors in PEV battery charging applications," 2015 IEEE Applied Power Electronics Conference and Exposition (APEC), Charlotte, NC, 2015, pp. 586-591,

[13] R. Chen and J.S. Lai, "Analysis and design of DCM SEPIC PFC with adjustable output voltage," Applied Power Electronics Conference and Exposition (APEC) 2015 IEEE, pp. 477-484, 2015, March.

[14] C. Zheng, H. Ma, B. Gu et al., "An improved bridgeless SEPIC PFC rectifier with optimized magnetic utilization minimized circulating losses and reduced sensing noise," 2013 28th Annual IEEE Applied Power Electronics Conf. Exposition (APEC), pp. 1906-1911, 2013.

[15] P. J. S. Costa, C. H. Illa Font and T. B. Lazzarin, "A Family of SinglePhase Voltage-Doubler High-Power-Factor SEPIC Rectifiers Operating in DCM," in IEEE Transactions on Power Electronics, vol. 32, no. 6, pp. 4279-4290, June 2017.

[16] H. Ma, Y. Li, J.S. Lai, et al., "An improved bridgeless SEPIC converter without circulating losses and input-voltage sensing," IEEE J. Emerg. Sel. Top. Power Electron., vol. 6, no. 3, pp. 1447-1455, 2017.

[17] A.J. Sabzali, E.H. Ismail, M.A. Al Saffar et al., "New bridgeless DCM SEPIC and Cuk PFC rectifiers with low conduction and switching losses," IEEE Trans. Ind. Appl., vol. 47, no. 2, pp. 873-881, 2011.

[18] M. Sahid, A. Yatim and T. Taufik, "A new ac-dc converter using bridgeless SEPIC," IECON 2010-36th Annual Conf. IEEE Industrial Electronics Society, pp. 286-290, 2010.

[19] M. Mahdavi and H. Farzanehfard, "New bridgeless PFC converter with reduced components," 2011 Int. Conf. Electronic Devices Systems and Applications (ICEDSA), pp. 125-130, 2011.

[20] M. Mahdavi and H. Farzanehfard, "Bridgeless SEPIC PFC rectifier with reduced components and conduction losses," IEEE Trans. Ind. Electron., vol. 58, no. 9, pp. 4153-4160, 2011.

[21] Y. Liu, Y. Sun and M. Su, "A Control Method for Bridgeless Cuk/Sepic PFC Rectifier to Achieve Power Decoupling," in IEEE Transactions on Industrial Electronics, vol. 64, no. 9, pp. 7272-7276, Sept. 2017.

[22] E.H. Ismail, "Bridgeless SEPIC rectifier with unity power factor and reduced conduction losses," IEEE Trans. Ind. Electron., vol. 56, no. 4, pp. 1147-1157, 2009.

[23] V. Bist, B. Singh, A. Chandra et al., "An adjustable speed PFC bridgeless-SEPIC fed brushless dc motor drive," 2015 IEEE Energy Conversion Congress and Exposition (ECCE), pp. 4886-4893, 2015.

[24] A.M. Al Gabri, A.A. Fardoun and E.H. Ismail, "Bridgeless PFCmodified SEPIC rectifier with extended gain for universal input voltage applications", IEEE Trans. Power Electron., vol. 30, no. 8, pp. 42724282,2014

[25] Xia Shen, Tiesheng Yan, Qi Li, Yingmin Wang, Weirong Chen, "Variable on-time controlled boundary conduction mode single-ended primary inductor converter power factor correction converter", Electronics Letters, vol. 54, no. 2, pp. 97-99, 2018.

[26] B. Singh and R. Kushwaha, "A PFC Based EV Battery Charger Using a Bridgeless Isolated SEPIC Converter," in IEEE Transactions on Industry Applications, vol. 56, no. 1, pp. 477-487, Jan.-Feb. 2020.

[27] M. R. Sahid, A. H. M. Yatim and T. Taufik, "A new AC-DC converter using bridgeless SEPIC," IECON 2010 - 36th Annual Conference on IEEE Industrial Electronics Society, Glendale, AZ, 2010, pp. 286-290.

[28] Y. Onal and Y. Sozer, "Bridgeless SEPIC PFC converter for low total harmonic distortion and high power factor," 2016 IEEE Applied Power Electronics Conference and Exposition (APEC), Long Beach, CA, 2016, pp. 2693-2699.

[29] R. Kushwaha and B. Singh, "An Improved SEPIC PFC Converter for Electric Vehicle Battery Charger," 2019 IEEE Industry Applications Society Annual Meeting, Baltimore, MD, USA, 2019, pp. 1-8. 


\section{IEEE POWER ELECTRONICS REGULAR PAPER}

[30] C. Shen, Y. Wu and C. Tsai, "Coupled-inductor Sepic-type PFC with soft-switching feature for LED lighting applications," 2011 6th IEEE Conference on Industrial Electronics and Applications, Beijing, 2011, pp. 2384-2389,

[31] P. Athalye, D. Maksimovic, and R. Erickson, "Improving efficiency of the active-clamped SEPIC rectifier at high line frequencies," in Proc. 20th Annu. IEEE Appl. Power Electron. Conf. Expo. (APEC), vol. 2, Mar. 2005, pp. 1152-1157.

[32] Andersen MAE, inventor. Bidirectional switched mode resonant type acdc converter and method for operating a bidirectional switched mode resonant type ac-dc converter. H02M 7/ 48 A I. 2019 Nov 7.

[33] Z.-W. Xu, Z.-L. Zhang, K. Xu, Z. Dong and X. Ren, "2-MHz GaN PWM isolated SEPIC converters", 2017 IEEE Applied Power Electronics Conference and Exposition (APEC), 2017.

[34] Y. Dou, Z. Ouyang, P. Thummala and M. A. E. Andersen, "PCB embedded inductor for high-frequency ZVS SEPIC converter," 2018 IEEE Applied Power Electronics Conference and Exposition (APEC), San Antonio, TX, 2018, pp. 98-104,

[35] B. Ulrich, "Analysis of a ZVS Synchronous Sepic/Zeta DC/DC Converter," PCIM Europe 2018; International Exhibition and Conference for Power Electronics, Intelligent Motion, Renewable Energy and Energy Management, Nuremberg, Germany, 2018, pp. 1-8.

[36] T. Nussbaumer, K. Raggl and J. W. Kolar, "Design Guidelines for Interleaved Single-Phase Boost PFC Circuits," in IEEE Transactions on Industrial Electronics, vol. 56, no. 7, pp. 2559-2573, July 2009.

[37] Pavana Prabhu, Vinatha Urundady, "Design of coupled inductors using split winding scheme for bridgeless SEPIC", Power Electronics IET, vol. 13, no. 7, pp. 1434-1444, 2020.

[38] X. Huang, F. C. Lee, Q. Li and W. Du, "High-Frequency HighEfficiency GaN-Based Interleaved CRM Bidirectional Buck/Boost Converter with Inverse Coupled Inductor," in IEEE Transactions on Power Electronics, vol. 31, no. 6, pp. 4343-4352, June 2016.

[39] Z. Liu, F. C. Lee, Q. Li and Y. Yang, "Design of GaN-Based MHz Totem-Pole PFC Rectifier," in IEEE Journal of Emerging and Selected Topics in Power Electronics, vol. 4, no. 3, pp. 799-807, Sept. 2016.

[40] Z. Liu, Z. Huang, F. C. Lee, Q. Li and Y. Yang, "Operation analysis of digital control based MHz totem-pole PFC with GaN device," 2015 IEEE 3rd Workshop on Wide Bandgap Power Devices and Applications (WiPDA), Blacksburg, VA, 2015, pp. 281-286.

[41] Z. Liu, X. Huang, M. Mu, Y. Yang, F. C. Lee and Q. Li, "Design and evaluation of GaN-based dual-phase interleaved $\mathrm{MHz}$ critical mode PFC converter," 2014 IEEE Energy Conversion Congress and Exposition (ECCE), Pittsburgh, PA, 2014, pp. 611-616.

[42] Chen M, Araghchini M, Afridi K K, et al. A Systematic Approach to Modeling Impedances and Current Distribution in Planar Magnetics [J]. IEEE Transactions on Power Electronics, 2016, 31(1): 560-80.

[43] Ayachit A, Kazimierczuk M K. Sensitivity of effective relative permeability for gapped magnetic cores with fringing effect [J]. IET Circuits, Devices \& Systems, 2017, 11(3): 209-15.

[44] X. Ren, Y. Zhou, Z. Guo, Y. Wu, Z. Zhang and Q. Chen, "Simple Analog-Based Accurate Variable On-Time Control for Critical Conduction Mode Boost Power Factor Correction Converters," in IEEE Journal of Emerging and Selected Topics in Power Electronics, vol. 8, no. 4, pp. 4025-4036, Dec. 2020.

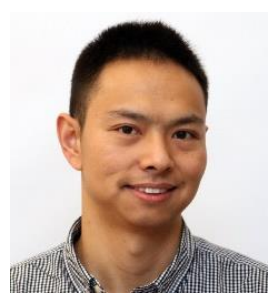

Yunfeng Liu (S'19) received the M.Sc. degree in electrical engineering from $\mathrm{Xi}$ an Jiaotong University, China in 2016. From 2016 to 2018, he was a senior Research and Development Engineer in the areas of power electronics in Delta Electronics. $\mathrm{He}$ is currently working toward the Ph.D. degree at Technical University of Denmark. His research focuses on design of high-frequency high power density AC-DC converters, High power bidirectional DC-DC converter, modelling for magnetic components, digital controller design, wireless power transfer.

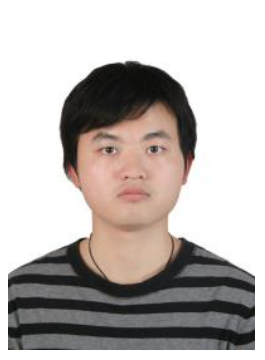

Xiaosheng Huang (M'20) received his B.E. and Ph.D. degree in 2009 and 2015 from Fuzhou University, Fuzhou, China respectively. $\mathrm{He}$ is currently working as an associate professor in the School of Electronic, Electrical Engineering and Physics, Fujian University of Technology, Fuzhou, China. $\mathrm{He}$ is also with the Fujian Provincial University Engineering Research Center for Industrial Automation, Fujian University of Technology. He is a member of the Magnetic Component Specialty Committee of the China Power Supply Society. His current research interests include power conversion, high-frequency magnetics, wireless power transfer, and electromagnetic field analysis and applications.

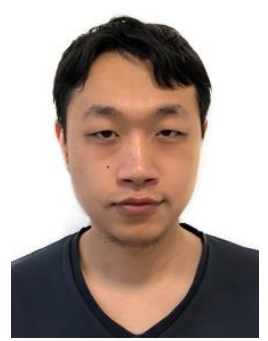

Yi Dou (S'17) received the B.S. degree in electrical engineering from $\mathrm{Xi}$ an Jiaotong University, China and M.Sc. degree in power electronics from Technical University of Denmark, Denmark in 2016 and 2018, respectively. He is currently working toward the Ph.D. degree at Technical University of Denmark. His research focuses on design of highfrequency/ very-high-frequency DC-DC converters, modelling for magnetic components, and modelling and optimization of $\mathrm{MHz}$-range wireless power transfer systems.

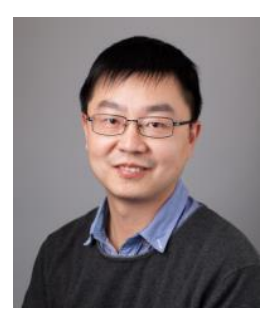

Ziwei Ouyang (S'07, M'11, SM'17) received his $\mathrm{PhD}$ degree from Technical University of Denmark (DTU) in 2011. From 2011 to 2013, he was a postdoc researcher at DTU. From 2013 to 2016, he was appointed as an assistant professor at the same department. Since from April 2016, he is an associate professor at DTU. His research areas focus on highfrequency planar magnetics modeling and integration, high-density high efficiency power converters, PV battery energy storage system, and wireless charging etc. He is IEEE senior member. He has over 70 high impact IEEE journal and conference publications, co-author on a book chapter on Magnetics for the "Handbook of Power Electronics" and currently he is the holder of 8 international patents. He was a recipient of Young Engineer Award at PCIM Asia 2014, and received Best Ph.D. Dissertation of the Year Award 2012 in Technical University of Denmark. He received several Best Paper Awards in IEEE sponsored international conferences. He has been invited to give lectures in many universities, enterprises and educational seminars and workshops around the world including USA, Europe and China. $\mathrm{He}$ has served as session chair in some IEEE sponsored conferences and associated editor for IEEE Journal of Emerging and Selected Topics in Power Electronics.

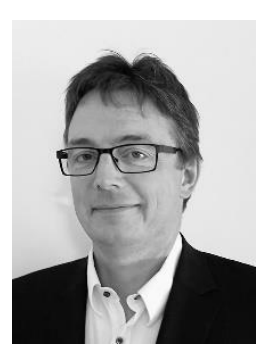

Michael A. E. Andersen (M'88) received the M.Sc.E.E. and Ph.D. degrees in power electronics from the Technical University of Denmark, Kongens Lyngby, Denmark, in 1987 and 1990, respectively. He is currently a Professor of power electronics at the Technical University of Denmark, where since 2009, he has been the Deputy Head of the Department of Electrical Engineering. He is the author or coauthor of more than 300 publications. His research interests include switch-mode power supplies, piezoelectric transformers, power factor correction, and switchmode audio power amplifiers. 